\title{
EXPLOTACIÓN DE OBSIDIANAS EN LA MESETA CENTRAL DE SANTA CRUZ. ESTRATEGIAS DE PRODUCCIÓN, USO Y CIRCULACIÓN ${ }^{1}$
}

\author{
EXPLOITATION OF OBSIDIAN IN THE CENTRAL PLATEAU OF SANTA CRUZ. \\ STRATEGIES OF PRODUCTION, USE AND CIRCULATION
}

\author{
Manuel Cueto ${ }^{2}$, Ariel D. Frank ${ }^{2}$ y Fabiana Skarbun ${ }^{2}$
}

\begin{abstract}
En este trabajo examinamos las estrategias de aprovisionamiento, explotación, circulación y consumo de la obsidiana hallada en sitios de las localidades arqueológicas La María y Cerro Tres Tetas (Meseta Central de Santa Cruz, Argentina). Llevamos a cabo el análisis tecnomorfológico, funcional y geoquímico de los restos de esta materia prima. Los resultados indican que la obsidiana procede de Pampa del Asador, fuente distante a más de $125 \mathrm{~km}$. Se registró un aumento de la explotación de esta materia prima a través del tiempo, identificándose dos grandes momentos. Durante el Pleistoceno Final/Holoceno Temprano, la misma no habría jugado un rol relevante en la organización tecnológica. Las secuencias de producción se caracterizan por el ingreso a los sitios de artefactos probablemente ya manufacturados. Durante el Holoceno Medio y Tardío se habrían ingresado a las localidades nódulos y/o núcleos. Las estrategias involucradas en su manufactura concuerdan en general con las implementadas para litologías locales y no exponen elementos que indiquen una mayor valorización de la obsidiana. No es posible asociar la gestión de esta roca a una estrategia de explotación eventual. Consideramos que la materia prima se obtenía en el marco de circuitos de movilidad y contactos intergrupales.
\end{abstract}

Palabras claves: obsidiana, Patagonia, análisis de procedencia, explotación/consumo, circulación.

In this paper, we examine the strategies of supply, exploitation, circulation and consumption of the obsidian found in sites from the archaeological localities of La María and Cerro Tres Tetas (Central Plateau of Santa Cruz province, Argentina). Technomorphologic, functional and geochemical analyses of the obsidian remains from these localities were carried out. Results show that obsidian comes from Pampa del Asador a source located over $125 \mathrm{~km}$ from the sites. Two chronological moments in the exploitation of this raw material were identified with an increase in consumption over time. During the Final Pleistocene/Early Holocene, obsidian was not a significant resource in the technological organization. Production sequences indicate that tools may have arrived already manufactured to the sites. In contrast, in the Middle and Late Holocene, cores and/or nodules were brought to the localities. Production strategies are similar to the ones recorded for local raw materials. There is no evidence to indicate that obsidian was a more valued resource than local rocks. We cannot ascertain that obsidian acquisition was part of a sporadic exploitation strategy from the source region. We believe that this raw material was obtained in mobility circuits and from intergroup contact.

Key words: Obsidian, Patagonia, provenance, exploitation/consumption, circulation.

A lo largo de la Patagonia, los contextos de ocupación humana fechados para el Holoceno Tardío, muestran numerosas evidencias de restos materiales que proceden de zonas lejanas a las que fueron recuperadas. Estos restos han sido a menudo interpretados como el producto del intercambio (Bate 2014; Gómez Otero y Stern 2005; Zubimendi y Ambrústolo 2011), dando cuenta del contacto, ya sea entre grupos diferentes o bien entre distintos segmentos de la misma sociedad. En contextos más tempranos, este tipo de evidencias suelen ser fragmentarias, dificultando proponer la existencia de instancias de intercambio.

\footnotetext{
1 Una primera versión de este artículo fue presentada en el simposio "Desde las fuentes: estudios de selección y aprovisionamiento de minerales. Implicancias en la producción lítica, alfarera, metalúrgica y de manifestaciones rupestres", en el marco del XIX Congreso Nacional de Arqueología Argentina, Tucumán (agosto 2016). Este manuscrito fue evaluado por pares externos y editado por el Comité Editorial de Chungara.

2 Consejo Nacional de Investigaciones Científicas y Técnicas (CONICET)/ División Arqueología, Facultad de Ciencias Naturales y Museo, Universidad Nacional de La Plata. Laboratorio 107, Edificio ANEXO Museo. 60 y 122 s/n (1900), La Plata, Buenos Aires, Argentina.manuelcueto@fcnym.unlp.edu.ar; frank.ariel@gmail.com; fskarbun@fcnym.unlp.edu.ar
}

Recibido: diciembre 2016. Aceptado: diciembre 2017.

http://dx.doi.org/10.4067/S0717-73562018005000502. Publicado en línea: 4-abril-2018. 
Diversas propuestas etnográficas y etnohistóricas, así como modelos teóricos, refieren que las interacciones sociales son constitutivas de las sociedades cazadorasrecolectoras, siendo fundamentales para su reproducción (Bate 2014; Nacuzzi 2007), puesto que trascienden el ámbito meramente económico. En las instancias de reunión, además de diversas formas de intercambio, se generan alianzas y lazos sociales, se realizan matrimonios, fiestas, rituales y a su vez se comparten noticias, entre otros. La presencia de bienes exóticos, sin embargo, no es en sí demostrativa del intercambio. Los mismos recursos pueden ser obtenidos por el grupo a través del acceso directo, implicando circuitos de movilidad más amplios (Meltzer 1989).

Distintos modelos heurísticos y matemáticos han sido empleados para evaluar la circulación y distribución de materias primas (p.ej. Renfrew 1977), sin embargo, estos presentan ciertos problemas. Entre ellos, Tykot (1996) menciona que estos modelos no consideran variaciones en los comportamientos, cambios demográficos ni la posibilidad de que distintos mecanismos estén actuando al mismo tiempo. Además, existe un problema de equifinalidad dado que distintos mecanismos de aprovisionamiento pueden generar similares patrones artefactuales (Meltzer 1989; Tykot 1996). En este sentido, se resalta la importancia de tener un corpus cuantitativo robusto de información. Asimismo deben analizarse las particularidades sociales (p.ej. históricas, geográficas, y/o ambientales) de cada caso para poder realizar inferencias sobre una buena base empírica (Newlander 2012; Tykot 1996).

En el caso particular de la Meseta Central de Santa Cruz, en la Patagonia meridional, esta fue habitada por sociedades cazadoras recolectoras desde el Pleistoceno Final hasta momentos históricos recientes (Borrero 2001; Miotti y Salemme 2004; Paunero 2009). Estas ocupaciones se evidencian en sitios reparados como cuevas y aleros tanto como al aire libre. Los primeros suelen ser sitios estratificados y multicomponentes, y sus registros más antiguos datan de ca. 11.000 años a.p. Se emplazan en sectores cercanos a fuentes de agua y frecuentemente formaron parte de campamentos de mayor tamaño. En ellos se realizaron labores diversas, aunque en ocasiones funcionaron sólo para tareas específicas -procesamiento primario y secundario, talleres, sitios de caza, divisaderos o uso ceremonial- (Cueto 2015; Paunero et al. 2005; Skarbun 2011). Cuentan en su proximidad con abundantes fuentes primarias y secundarias de materias primas silíceas de muy buena calidad para la talla, que fueron recurrentemente utilizadas por las sociedades que allí habitaron. Las evidencias de ocupación al aire libre se suelen presentar de manera superficial, en sectores con disponibilidad variable de recursos y características adecuadas para el emplazamiento de los grupos.

En Patagonia, se ha venido discutiendo la circulación de obsidianas, las cuales han sido identificadas en lugares distantes de sus fuentes. En particular en la Meseta Central no se conocen fuentes de esta materia prima y la más cercana se ubica al menos a $125 \mathrm{~km}$ al oeste de los sitios excavados. Esto ha generado preguntas sobre su importancia para las sociedades cazadorasrecolectoras pasadas, el modo de aprovisionamiento, las practicas tecnológicas, la movilidad y las rutas de circulación e interacción humanas, entre otras (Ambrústolo et al. 2012; Belardi et al. 2006; Espinosa y Goñi 1999; Gómez Otero y Stern 2005; Hermo y Miotti 2010; Pallo y Borrero 2015). Si bien se han formulado diversas interpretaciones, no se han realizado estudios en profundidad que articulen la caracterización geoquímica, tecnológica y funcional para conjuntos lo suficientemente amplios.

En este trabajo, evaluamos las estrategias de producción y consumo desarrolladas a través del tiempo con la obsidiana. Analizamos las piezas procedentes de los sitios ubicados en las localidades arqueológicas La María y Cerro Tres Tetas, en la Meseta Central de Santa Cruz (Figura 1) y establecemos paralelismos con las tendencias propuestas para otros sitios de la región. A su vez, comparamos los procesos de manufactura inferidos para esta materia prima respecto de aquellos seguidos con rocas locales en el área de estudio, discutiendo el rol social asignado a la obsidiana. El propósito es aportar información que nos permita discutir la circulación de esta materia prima, reflexionar sobre las estrategias de aprovisionamiento y presentar ideas sobre los vínculos que mantuvieron las sociedades que ocuparon la región y sus áreas vecinas.

\section{Antecedentes: La Obsidiana en la Meseta Central de Santa Cruz}

La procedencia de los restos de obsidiana encontrados en los sitios arqueológicos de Patagonia meridional (al sur del paralelo $46^{\circ} \mathrm{S}$ ) ha sido cuestión de debate y especulación durante bastante tiempo (Aguerre 2003; Civalero 1999; MansurFranchomme 1984; Stern 1999). Las primeras menciones sobre lugares donde se disponía de esta materia prima fueron realizadas por viajeros a fines del siglo XIX y principios del XX (Musters 2005; Onelli 1904). Sin embargo, las fuentes no fueron identificadas sino hasta la década de 1990, gracias a la articulación de las prospecciones sistemáticas en 


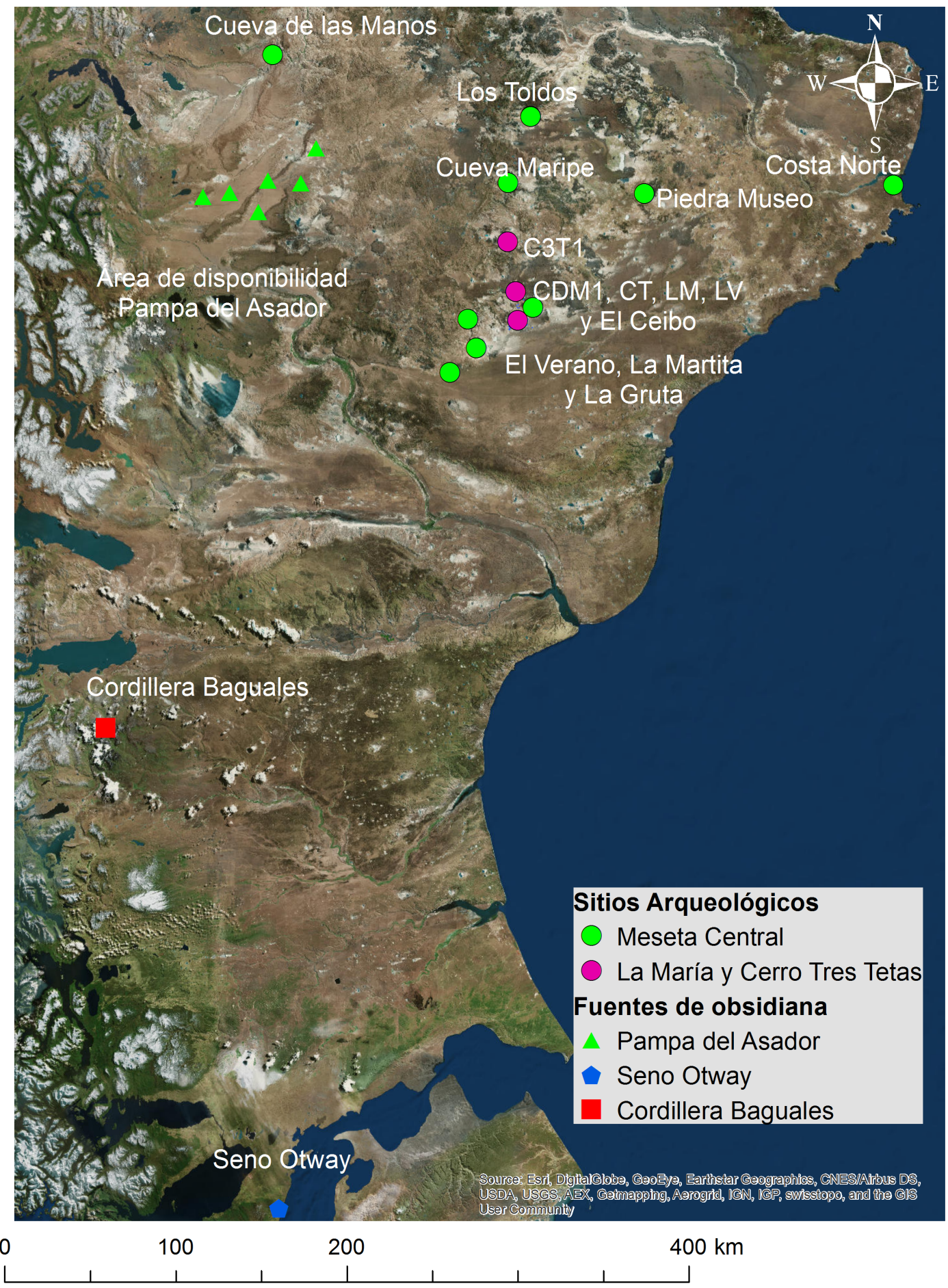

Figura. 1. Fuentes y sitios con obsidiana en la Meseta Central. C3T1: Cerro Tres Tetas 1. CDM1: Casa del Minero 1. CT: Cueva Túnel. LM: La Mesada. LV: Cueva de la Ventana. Sources and sites in the Central Plateau with obsidian. C3T1: Cerro Tres Tetas 1. CDM1: Casa del Minero 1. CT: Cueva Túnel. $L M$ : La Mesada. $L V$ : Cueva de la Ventana. 
terreno, el examen riguroso de los restos arqueológicos y la implementación de análisis geoquímicos (Espinosa y Goñi 1999; Stern y Franco 2000; Stern y Prieto 1991; Stern et al. 1995).

Hasta el momento se han reconocido tres clases de obsidiana que corresponderían a tres fuentes diferentes: Pampa del Asador (PDA), Cordillera Baguales y Seno Otway (Stern 2004). Todas ellas se ubicarían en la porción occidental de esta región (Figura 1), y se pueden diferenciar tanto a nivel macroscópico, por su color, como a nivel de sus características geoquímicas (Fernández y Leal 2014; Stern 2004).

La fuente conocida como Cordillera Baguales se supone que se ubica a $340 \mathrm{~km}$ al suroeste de los sitios analizados en este trabajo. Este tipo de obsidiana se ha identificado mediante el análisis de piezas arqueológicas. Se caracteriza por ser de color gris-verdosa veteada y sus restos han sido hallados en proximidades del Lago Argentino, siendo menos habituales en otros sectores (Stern 2004). El tipo Seno Otway se identificó a partir del análisis de restos arqueológicos de sitios próximos al mar de Otway. La ubicación precisa de la fuente se desconoce; se estima su localización a unos 525 $\mathrm{km}$ al suroeste de los sitios aquí analizados. La roca es de color verde oscuro o gris, con vetas; y se presentaría en la fuente a modo de fragmentos individuales de brechas (San Román y Prieto 2004; Stern y Prieto 1991). PDA es una fuente secundaria (Espinosa y Goñi 1999) que posee un área de disponibilidad de ca. $2000 \mathrm{~km}^{2}$ (cálculo basado en la figura 2 de Belardi et al. 2006); la fuente primaria o bien ya no existe o aún no ha sido hallada. El sector de disponibilidad natural de esta materia prima más cercano a nuestra área de estudio es el abanico aluvial (Belardi et al. 2006), el cual se ubica a una distancia que fluctúa entre los 125 y los $150 \mathrm{~km}$. La obsidiana es negra o gris traslúcida y ocasionalmente tiene vetas marrones. En general muestra texturas homogéneas, aunque puede presentar cristales de plagioclasa (Stern 2004). En esta fuente se identificaron por análisis de elementos traza y activación neutrónica tres variedades. Son rodados de tamaños que varían entre 3 y $6 \mathrm{~cm}$, con superficie meteorizada y corteza opaca con vesículas (Belardi et al. 2006). La obsidiana de PDA ha sido intensamente empleada en la Patagonia a lo largo del tiempo, y fue recuperada en contextos distantes a más de $800 \mathrm{~km}$ de su emplazamiento natural (Gómez Otero y Stern 2005).

La información disponible hasta el momento acerca de los artefactos de obsidiana hallados en sitios de la Meseta Central es desigual. Una revisión integral de la bibliografía demuestra que si bien algunos pocos trabajos presentan información detallada y datos cuantitativos claros, en la mayor parte de los casos la evidencia descripta es fragmentaria. En ocasiones existen menciones aisladas, en otras faltan datos cuantitativos o bien se consignan referencias a un grupo tipológico particular (Aguerre 2003; Cardich y Flegenheimer 1978; Cardich et al. 1981-1982; Cardich et al. 19931994; Castro 1994; Crivelli Montero 1976-1980; Durán 1986-1987; Durán et al. 2003; Franco et al. 2010; Hermo 2008; Hermo y Miotti 2010). Por ello, consideramos que las tendencias observadas deben ser tratadas con cautela.

Para la Meseta Central fueron realizados pocos estudios geoquímicos hasta el momento. Se trata de ocho muestras procedentes de dos sitios (La Martita y AEP1) que fueron analizadas a finales de la década de 1990. Los resultados indicaron que estos materiales procederían de PDA (García-Herbst et al. 2007; Stern 1999).

Los sitios arqueológicos presentan evidencias de explotación de obsidiana desde los primeros momentos de ocupación (Figura 1). Para el Pleistoceno Final (12.000-10.000 años ${ }^{14} \mathrm{C}$ a.p.) se registró esta roca en Cerro Tres Tetas 1 (Paunero 1993-94; Stern 2004), La Gruta (tres restos) (Franco et al. 2010) y Los Toldos 3 (cuatro lascas) (Cardich y Flegenheimer 1978). Además Cardich et al. (1981-82) consignan la presencia de un cuchillo de esta litología en la Cueva 7 de El Ceibo. Durante el Holoceno Temprano (10.000-7.500 años ${ }^{14} \mathrm{C}$ a.p.) aumentaría la cantidad, variedad y tamaño de los artefactos confeccionados con esta materia prima. Entre los instrumentos dominan las puntas de proyectil apedunculadas (Aguerre 2003; Cardich y Flegenheimer 1978; Cardich et al. 1981-82; Cardich et al. 1993-1994; Durán et al. 2003; Hermo y Miotti 2010). De acuerdo a Hermo y Miotti (2010:117) el uso de la obsidiana como "materia prima para la confección casi exclusiva de puntas de proyectil tendría mayor ligazón con las formas de apropiación y circulación de las rocas y de los bienes de alto contenido simbólico, que con necesidades estrictamente técnicas". Estos autores proponen que las puntas de obsidiana habrían ingresado al área por intercambio. Tres muestras del sitio AEP1 y dos del sitio La Martita fueron analizadas por ICP-MS indicando procedencia de PDA.

En el Holoceno Medio (7.500-3.500 años ${ }^{14} \mathrm{C}$ a.p.) hay obsidiana prácticamente en todos los sitios. En cuanto a las tareas de producción predominan la talla del núcleo y la formatización final de artefactos. Se recuperaron pocos instrumentos, en general unifaciales (incluyendo raspadores, 
lascas y láminas retocadas) confeccionados sobre hojas, aumentando la producción de estas. Se identificaron núcleos piramidales pequeños con negativos de lascas y hojas, con reserva de corteza, prácticamente agotados (Cardich et al. 1993-1994; Crivelli Montero 1976-1980; Durán 1986-1987; Hermo 2008; Hermo y Miotti 2010). Según Hermo y Miotti (2010), los procedimientos técnicos empleados para la confección de hojas de obsidiana son los mismos que los dedicados para esta tecnología en rocas locales. Sin embargo, plantean diferencias en la cadena operativa, teniendo en cuenta la obtención, el uso de filos naturales y el menor tamaño y variación en dimensiones de las hojas confeccionadas en esta roca (Hermo y Miotti 2010:121).

Durante el Holoceno Tardío (3.500-200 años ${ }^{14} \mathrm{C}$ a.p.) existe mayor variabilidad artefactual aunque hay continuidad en la producción de hojas, registrándose también puntas de proyectil y raspadores (Durán 1986-1987; Hermo y Miotti 2010). Dos muestras (una de AEP1 y otra de La Martita) fueron analizadas geoquímicamente y proceden de PDA. Para los sitios ubicados en el norte de la costa santacruceña (de ahora en más Costa Norte), la proporción de artefactos de obsidiana es baja. Predominan eventos de talla intermedios y en menor medida iniciales (Ambrústolo et al. 2012:82). Los productos de la talla son principalmente internos, aunque el $20 \%$ de las piezas tienen corteza. Las piezas suelen ser de tamaño muy chico, no se recuperaron artefactos formatizados ni núcleos (Ambrústolo et al. 2012). Esta roca habría sido transportada hasta la costa en forma de rodados o núcleos por aprovisionamiento directo o intercambio con poblaciones del interior (Ambrústolo et al. 2012). A su vez Hermo y Miotti (2010) sugieren que en el Holoceno Medio y Tardío, la obsidiana habría ingresado a la Meseta Central en forma de nódulos, que constituirían "Bienes Altamente Valorados", con significación estética y social. Por el contrario, Pallo y Borrero (2015:297), sobre la base de una baja proporción de obsidianas en el registro, rechazan la idea de un acceso a esta roca por intercambio en áreas lejanas a la fuente (incluyendo la Meseta Central), proponiendo su ingreso a esta región como "transportes modelables como riders acompañando a visitantes". Entienden las visitas como "el movimiento de gente sin el propósito específico de realizar intercambio -participar en cacerías, controlar recursos u otras actividades-" (Pallo y Borrero 2015:299), lo cual generaría la depositación eventual de estos materiales lejos de la fuente.

\section{Metodología}

Analizamos la totalidad de restos de obsidiana de los componentes del Pleistoceno Final: Cerro Tres Tetas 1 (C3T1) Nivel 5; del Holoceno Temprano: Casa del Minero 1 (CDM1) Nivel 3 Medio, Cueva de La Ventana (LV) Nivel 6, La Mesada (LM) Nivel 8; del Holoceno Medio: C3T1 Nivel 4, CDM1 Nivel 3 Superior, LV Nivel 4 y 5, LM Nivel 5b y 6; y del Holoceno Tardío: CDM1 Nivel 1 y 2 . En total se registraron 368 artefactos de esta materia prima. Se trata de sitios multiestratigráficos en cuevas (ver fechados en Cueto 2015; Frank 2011; Paunero 2000; Skarbun 2011).

La identificación de la materia prima se llevó a cabo macroscópicamente, diferenciando las piezas de obsidiana de las otras rocas, según sus características diagnósticas (color, brillo, transparencia, textura, inclusiones, corteza, granulometría, entre otras).

Efectuamos una clasificación de los conjuntos de manera integradora y flexible buscando articular atributos morfológicos, técnicos y funcionales. Desde nuestro punto de vista el proceso de producción es un procedimiento complejo que está guiado por la función específica para la cual fue producida la herramienta, como las actividades más amplias en las cuales se inserta. Este enfoque contempla la organización de la sociedad que emplea dichos instrumentos y las características del paisaje en el cual estas tareas se desarrollan (Cueto 2015; Cueto et al. 2014; Frank 2011; Skarbun 2011).

La clasificación tecnomorfológica se hizo en base a diversas propuestas del ámbito local y regional (Aschero 1975; Cardich y Flegenheimer 1978; Cardich et al. 1981-82; Cueto et al. 2012; Frank 2011; Paunero y Castro 2001; Skarbun 2011; entre otros), y fue complementada con sugerencias procedentes de la literatura internacional (Andrefsky 2005; Tixier et al. 1980; entre otros). El estudio tecnológico involucró la determinación del estadio de reducción en el que se inscriben los artefactos, analizándose tanto los productos de talla como los artefactos formatizados. Se ordenan los artefactos según los siguientes pasos técnicos: preparación/ reducción inicial del núcleo (descortezamiento); talla del núcleo y extracción de soportes; formatización final de los artefactos -retalla, retoque y adelgazamiento bifacial- y reactivación de los filos (Cueto 2015; Cueto et al. 2014; Paunero 1993-94; Skarbun 2011). Los pasos considerados fueron formulados a partir de las propuestas de diversos autores (Collins 1989-90; Nami 1992; Tixier et al. 1980), de nuestras experimentaciones (Cueto 
2015; Cueto y Frank 2008-2010; Frank 2011), de los investigadores de la meseta que plantearon este tipo de estudios (Mansur-Franchomme 1984; Paunero 1993-94) y de nuestra propia experiencia en el análisis de la tecnología lítica.

Además se implementó el análisis funcional de base microscópica (Cueto 2015) sobre una muestra de 13 artefactos con el propósito de caracterizar su consumo en cuanto a sustancia procesada, acción y trabajo realizado. Los materiales se examinan según tres niveles de aproximación óptica, combinando el análisis macroscópico, el uso de lupa binocular $(10 \mathrm{X}$ a $90 \mathrm{X})$ y de microscopio metalográfico de campo claro y oscuro, con objetivos de larga distancia (75X-300X). De manera concurrente se consideran los caracteres de las huellas de uso (macro y microscópicas) definidos en estudios experimentales que implicaron la generación de colecciones de referencia con artefactos de roca utilizados en distintas acciones sobre diversas sustancias (Cueto 2015).

Para determinar la procedencia de las piezas de obsidiana, se realizó el análisis por ICP-MS de una muestra de 16 artefactos en la Universidad de Colorado (EE.UU.). El protocolo empleado puede consultarse en Fernández et al. (2015). Para la selección de los artefactos, se realizó un muestreo estratificado por período considerando las variedades de color, aunque limitado por las restricciones del método en cuanto al peso necesario de las piezas $(0,3 \mathrm{~g})$. Se analizó una pieza asignable al Pleistoceno final que corresponde al $10 \%$ del conjunto de este período, una del Holoceno Temprano (20\%), cuatro del Holoceno Medio $(3,42 \%)$ y diez del Holoceno Tardío (4,24\%; una de ellas procede del sitio El Rincón, Localidad Arqueológica Reserva Península San Julián, Tabla 1). Los resultados fueron interpretados por Stern (2016).

\section{Resultados: Tecnología, Función y Procedencia}

Las 368 piezas de obsidiana son en su mayoría de color negro, algunas levemente translúcidas, con vetas marrones o fenocristales, y otras de color gris. Para el Pleistoceno Final se hallaron 10 restos, que constituyen el 0,33\% de los artefactos del período, considerando todas las litologías ${ }^{1}$. Para el Holoceno Temprano la proporción de obsidiana asciende a $0,82 \%$ ( $n=5$; tres ocupaciones analizadas), mientras que para el Holoceno Medio esta litología representa el 2,69\% ( $\mathrm{n}=117)$ para las cuatro ocupaciones. Finalmente, en el único componente asignado al Holoceno Tardío se registra un 9,27\% ( $\mathrm{n}=236)$ de esta materia prima (Tabla 2; Figura 2).

En relación con la estructura general de los conjuntos en obsidiana, en todos los casos predominan los productos de la talla (Figura 3), habiendo escasos artefactos formatizados solo en los períodos finales del Holoceno. No se han registrado núcleos (Tabla 3 ).

La materia prima de los seis artefactos es de color negro, aunque una punta fragmentada tiene vetas marrones. Los artefactos formatizados (Tabla 4, Figura 4) registrados para el Holoceno Medio son una lámina retocada y una raedera. Ambos son unifaciales, tienen retoque marginal, están fracturados y no tienen corteza. Para el Holoceno Tardío se recuperaron dos puntas de proyectil bifaciales, un raspador/punta destacada y una lasca retocada, ambos unifaciales. Excepto una de las puntas, para la cual solo se halló un fragmento del limbo, el resto de los instrumentos se encuentran enteros. La punta entera es triangular apedunculada y mide $5 \mathrm{~cm}$ de longitud. La lasca retocada posee un solo filo y corteza escasa. En tanto, el raspador/ punta destacada tiene tres filos (dos retocados) y no posee corteza.

Las secuencias de producción artefactual (Tabla 5) muestran nulos (Pleistoceno Final y Holoceno Temprano) y bajos (Holoceno Medio y Tardío) porcentajes de piezas del descortezamiento (Figura $3 b)$. Hay porcentajes medios de piezas producidas durante la talla del núcleo y altos porcentajes de

\begin{tabular}{|c|c|c|c|c|c|}
\hline \multicolumn{6}{|c|}{$\begin{array}{l}\text { Tabla 1. Artefactos analizados por ICP-MS. L.t.n.: Lasca de talla de } \\
\text { núcleo; L.desc.: Lasca de descortezamiento; L.re.: Lasca de retalla; } \\
\text { L.f.f.: Lasca de formatización final. } \\
\text { Artifacts analyzed by ICP-MS. L.t.n.: Core reduction flake; L.desc.: } \\
\text { Decortication flake; L.re.: reflaking debitage; L.f.f.: Final shaping of } \\
\text { tools debitage. }\end{array}$} \\
\hline Período & Muestra & $\begin{array}{l}\text { Clase de } \\
\text { artefacto }\end{array}$ & Sitio & Nivel & Procedencia \\
\hline $\begin{array}{l}\text { Pleistoceno } \\
\text { Final }\end{array}$ & CS16 & & C3T1 & 5 & PDA2 \\
\hline $\begin{array}{l}\text { Holoceno } \\
\text { Temprano }\end{array}$ & CS01 & & LV & 6 & \multirow{5}{*}{ PDA1 } \\
\hline \multirow{4}{*}{$\begin{array}{l}\text { Holoceno } \\
\text { Medio }\end{array}$} & $\mathrm{CS} 02$ & L.t.n. & LM & 6 & \\
\hline & $\mathrm{CS} 03$ & & LV & 4 & \\
\hline & CS04 & & \multirow{2}{*}{ CDM1 } & \multirow{2}{*}{$\begin{array}{c}3 \\
\text { Superior }\end{array}$} & \\
\hline & $\mathrm{CS} 05$ & & & & \\
\hline \multirow{10}{*}{$\begin{array}{l}\text { Holoceno } \\
\text { Tardío }\end{array}$} & CS06 & L.des. & $\begin{array}{c}\text { El } \\
\text { Rincón }\end{array}$ & Superficial & PDA2 \\
\hline & CS07 & L.t.n. & \multirow{9}{*}{ CDM1 } & \multirow{6}{*}{2} & \multirow{2}{*}{ PDA1 } \\
\hline & CS08 & L.re. & & & \\
\hline & CS09 & \multirow{4}{*}{ L.t.n. } & & & \multirow{2}{*}{ PDA2 } \\
\hline & CS10 & & & & \\
\hline & CS11 & & & & PDA1 \\
\hline & CS12 & & & & PDA2 \\
\hline & CS13 & L.f.f. & & \multirow{2}{*}{1} & \multirow{2}{*}{ PDA1 } \\
\hline & CS14 & \multirow{2}{*}{ L.t.n. } & & & \\
\hline & CS15 & & & 2 & PDA2 \\
\hline
\end{tabular}


Tabla 2. Frecuencia de obsidiana (obs.) en cada ocupación. Total artef. líticos: Cantidad total de artefactos líticos recuperados en cada ocupación.C3T1: Cerro Tres Tetas 1. CDM1: Casa del Minero 1. CT: Cueva Túnel. LM: La Mesada. LV: Cueva de la Ventana.

Frequency of obsidian (obs.) in each occupation. Total artef. líticos: Total amount of lithic artifacts found in each occupation.C3T1: Cerro Tres Tetas 1. CDM1: Casa del Minero 1. CT: Cueva Túnel. LM: La Mesada. LV: Cueva de la Ventana.

\begin{tabular}{|c|c|c|c|c|c|c|c|c|c|c|c|c|}
\hline & & & & \multicolumn{9}{|c|}{ Holoceno } \\
\hline & \multicolumn{3}{|c|}{ Pleistoceno Final } & \multicolumn{3}{|c|}{ Temprano } & \multicolumn{3}{|c|}{ Medio } & \multicolumn{3}{|c|}{ Tardío } \\
\hline & $\begin{array}{l}\text { Total } \\
\text { artef. } \\
\text { líticos }\end{array}$ & $\begin{array}{c}\mathrm{n} \\
\text { obs. }\end{array}$ & $\begin{array}{c}\% \\
\text { obs. }\end{array}$ & $\begin{array}{l}\text { Total } \\
\text { artef. } \\
\text { líticos }\end{array}$ & $\begin{array}{c}\mathrm{n} \\
\text { obs. }\end{array}$ & $\begin{array}{c}\% \\
\text { obs. }\end{array}$ & $\begin{array}{l}\text { Total } \\
\text { artef. } \\
\text { líticos }\end{array}$ & $\begin{array}{c}\mathrm{n} \\
\text { obs. }\end{array}$ & $\begin{array}{c}\% \\
\text { obs. }\end{array}$ & $\begin{array}{l}\text { Total } \\
\text { artef. } \\
\text { líticos }\end{array}$ & $\begin{array}{c}\mathrm{n} \\
\text { obs. }\end{array}$ & $\begin{array}{c}\% \\
\text { obs. }\end{array}$ \\
\hline \multirow{2}{*}{ CDM1 } & 1.240 & 0 & 0 & \multirow{2}{*}{539} & \multirow{2}{*}{3} & \multirow{2}{*}{0,56} & \multirow{2}{*}{454} & \multirow{2}{*}{27} & \multirow{2}{*}{5,95} & \multirow{2}{*}{2.547} & \multirow{2}{*}{236} & \multirow{2}{*}{9,27} \\
\hline & 1.200 & 0 & 0 & & & & & & & & & \\
\hline LV & & & & 34 & 1 & 2,94 & 57 & 4 & 7,02 & & & \\
\hline LM & & & & 38 & 1 & 2,63 & 2.109 & 35 & 1,66 & & & \\
\hline $\mathrm{CT}$ & 113 & 0 & 0 & & & & & & & & & \\
\hline $\mathrm{C} 3 \mathrm{~T} 1$ & 514 & 10 & 1,95 & & & & 1.729 & 51 & 2,95 & & & \\
\hline Total & 3.067 & 10 & 0,33 & 611 & 5 & 0,82 & 4.349 & 117 & 2,69 & 2.547 & 236 & 9,27 \\
\hline
\end{tabular}

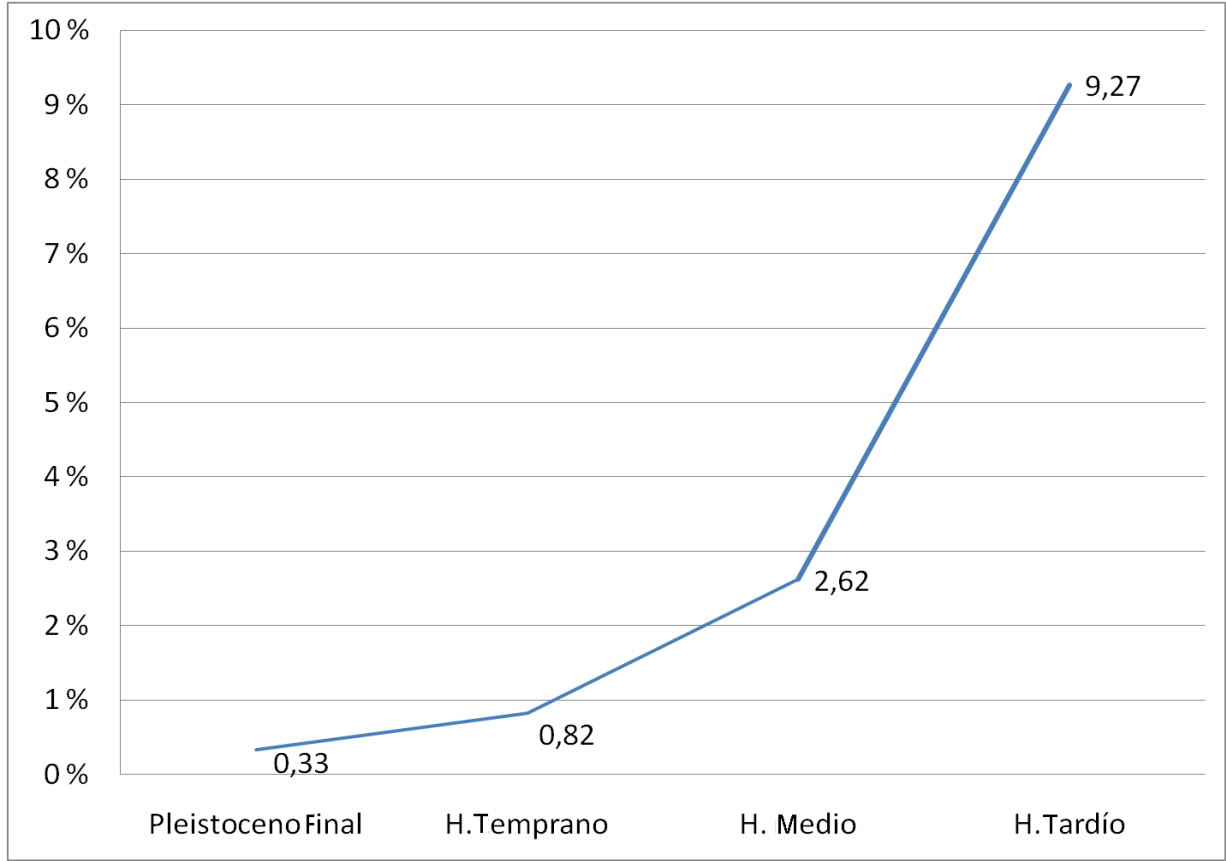

Figura 2. Proporción de restos de obsidiana por período.

Proportion of obsidian remains throughout time.

Tabla 3. Estructura de los conjuntos de obsidiana. AF: artefactos formatizados. XT: productos de talla. Structure of the obsidian assemblages. AF: tools. XT: debitage.

\begin{tabular}{|c|c|c|c|c|c|c|c|}
\hline \multicolumn{2}{|c|}{ Período } & $\begin{array}{c}\mathrm{n} \\
\mathrm{AF}\end{array}$ & $\begin{array}{c}\% \\
\mathrm{AF}\end{array}$ & $\begin{array}{c}\mathrm{n} \\
\mathrm{XT}\end{array}$ & $\begin{array}{c}\% \\
\text { XT }\end{array}$ & $\begin{array}{c}\mathrm{n} \\
\text { Total }\end{array}$ & $\begin{array}{c}\% \\
\text { Total }\end{array}$ \\
\hline \multicolumn{2}{|c|}{ Pleistoceno Final } & 0 & 0 & 10 & 100 & 10 & 100 \\
\hline \multirow{3}{*}{ Holoceno } & Temprano & 0 & 0 & 5 & 100 & 5 & 100 \\
\hline & Medio & 2 & 1,72 & 114 & 98,27 & 116 & 100 \\
\hline & Tardío & 4 & 1,69 & 232 & 98,31 & 236 & 100 \\
\hline \multicolumn{2}{|c|}{ Total } & 6 & 1,63 & 361 & 98,37 & 367 & 100 \\
\hline
\end{tabular}

productos de formatización final en todos los periodos. Los artefactos se tallaron por percusión y presión. Esta última técnica es notoria en las etapas finales de formatización durante el Holoceno Medio y Tardío. Son altos los porcentajes de piezas sin corteza y con corteza escasa (Figura 5).

Para el Pleistoceno Final y el Holoceno Temprano, de las piezas de formatización final se identificaron las producidas por el retoque y el microrretoque. Además estas fueron las más abundantes para 


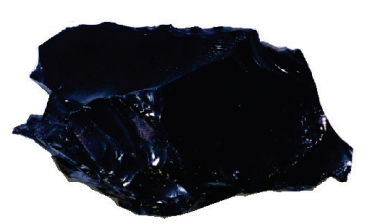

a

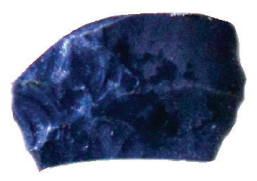

d

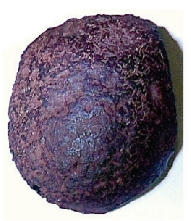

b

e

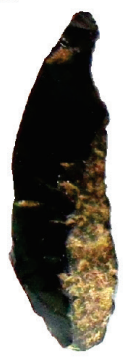

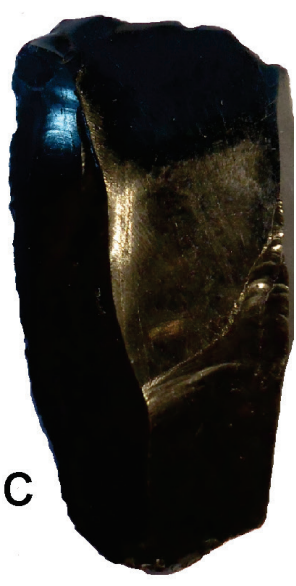
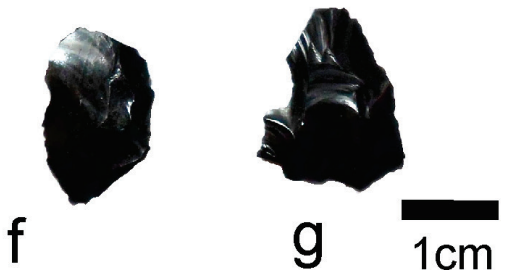

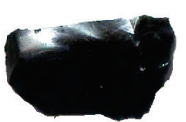

$\mathrm{h}$

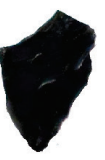

i

Figura 3. Productos de talla. a: Holoceno Temprano. b, d-e: Holoceno Medio. c, f-i: Holoceno Tardío. Debitage. a: Early Holocene. $b$, d-e: Middle Holocene. $c$, f-i: Late Holocene.

Tabla 4. Caracteres tecnológicos de los artefactos formatizados. RE: retalla; R: retoque; M: microrretoque.

Technological traits of the tools. RE: reflaking. R: retouch. M: microretouch.

\begin{tabular}{|c|c|c|c|c|c|c|c|c|}
\hline \multirow[b]{2}{*}{ Período } & \multirow[b]{2}{*}{ Clase } & \multirow{2}{*}{$\begin{array}{l}\text { Módulo } \\
\text { largo/ } \\
\text { ancho }\end{array}$} & \multirow{2}{*}{$\begin{array}{l}\text { Modulo } \\
\text { Ancho / } \\
\text { espesor }\end{array}$} & \multicolumn{5}{|c|}{ Filos } \\
\hline & & & & Tipo & Delineación & $\begin{array}{c}\text { Longitud } \\
(\mathrm{mm})\end{array}$ & Angulo & $\begin{array}{l}\text { Ancho de } \\
\text { lascados }\end{array}$ \\
\hline \multirow{5}{*}{$\begin{array}{l}\text { Holoceno } \\
\text { Medio }\end{array}$} & \multirow{2}{*}{$\begin{array}{l}\text { Lámina } \\
\text { retocada }\end{array}$} & \multirow{2}{*}{ chico } & \multirow{2}{*}{ medio } & Retocado & $\begin{array}{l}\text { Convexo } \\
\text { atenuado }\end{array}$ & 13 & $60^{\circ}$ & M \\
\hline & & & & Natural & $\begin{array}{l}\text { Levemente } \\
\text { cóncavo }\end{array}$ & 25 & $45^{\circ}$ & - \\
\hline & \multirow{3}{*}{ Raedera } & \multirow{3}{*}{ chico } & \multirow{3}{*}{ medio } & Retocado & Cóncavo & 27 & $41^{\circ}$ & R-M \\
\hline & & & & Retocado & $\begin{array}{l}\text { Convexo } \\
\text { atenuado }\end{array}$ & 19 & $50^{\circ}$ & $\mathrm{R}$ \\
\hline & & & & Retocado & Recto & 12 & $34^{\circ}$ & $\mathrm{R}$ \\
\hline \multirow{8}{*}{$\begin{array}{l}\text { Holoceno } \\
\text { Tardío }\end{array}$} & $\begin{array}{l}\text { Lasca } \\
\text { retocada }\end{array}$ & chico & delgado & Retocado & Convexo & 16 & $45^{\circ}$ & $\mathrm{R}-\mathrm{M}$ \\
\hline & \multirow{3}{*}{$\begin{array}{l}\text { Raspador/ } \\
\text { punta } \\
\text { destacada }\end{array}$} & \multirow{3}{*}{$\begin{array}{l}\text { muy } \\
\text { chico }\end{array}$} & \multirow{3}{*}{ medio } & Natural & Recto & 11 & $45^{\circ}$ & - \\
\hline & & & & $\begin{array}{c}\text { Punta } \\
\text { destacada }\end{array}$ & Punta & 3 & $60^{\circ}$ & R-M \\
\hline & & & & Raspador & $\begin{array}{l}\text { Levemente } \\
\text { cóncavo }\end{array}$ & 10 & $60^{\circ}$ & $\mathrm{R}-\mathrm{M}$ \\
\hline & \multirow{2}{*}{$\begin{array}{c}\text { Punta } \\
\text { bifacial }\end{array}$} & \multirow{2}{*}{$\begin{array}{l}\text { muy } \\
\text { chico }\end{array}$} & \multirow{2}{*}{ delgado } & Retocado & Recto & 14 & $30^{\circ}$ & RE-R-M \\
\hline & & & & Retocado & Recto & 14 & $30^{\circ}$ & RE-R-M \\
\hline & \multirow{2}{*}{$\begin{array}{l}\text { Punta } \\
\text { bifacial }\end{array}$} & \multirow{2}{*}{$\begin{array}{l}\text { medi- } \\
\text { ana }\end{array}$} & \multirow{2}{*}{ medio } & Retocado & Recto & 43 & $60^{\circ}$ & RE-R-M \\
\hline & & & & Retocado & Recto & 44 & $90^{\circ}$ & RE-R-M \\
\hline
\end{tabular}



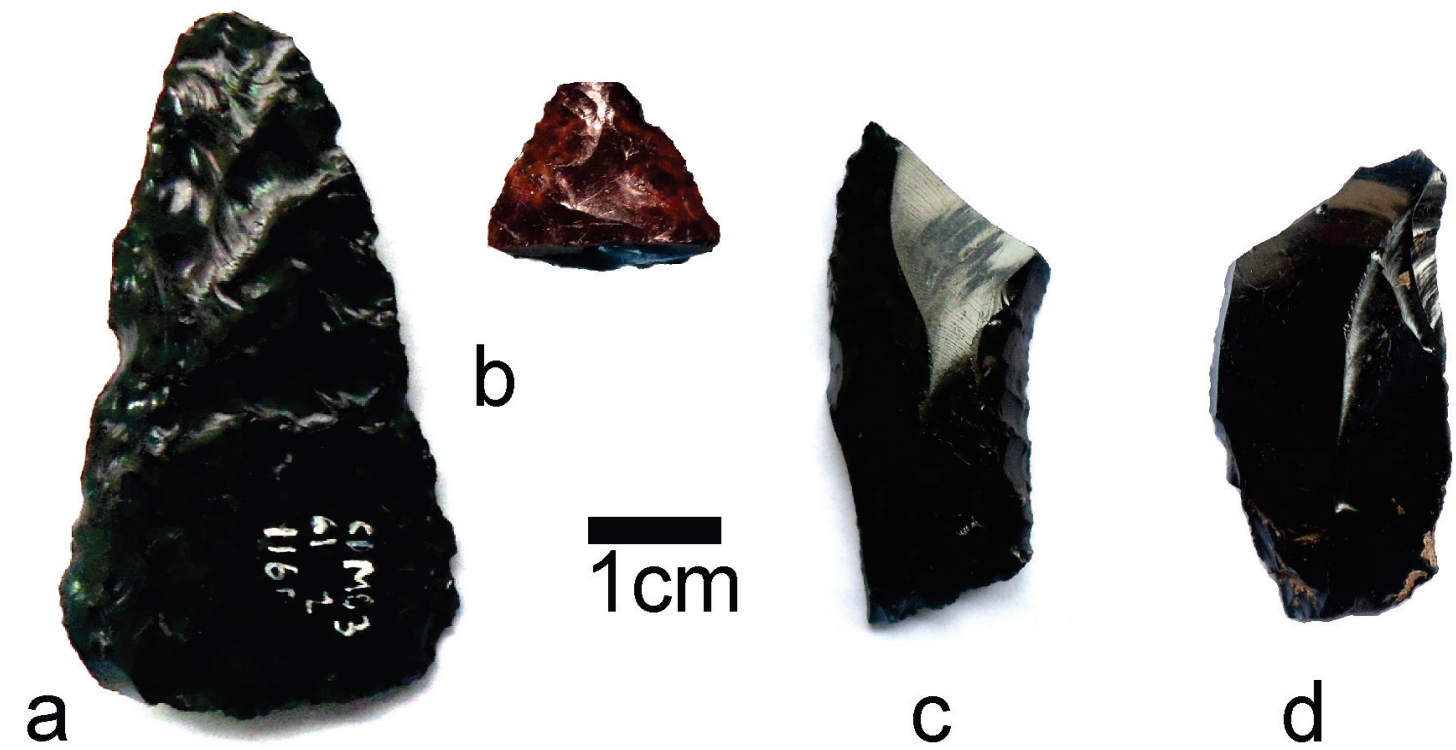

Figura 4. Artefactos formatizados. Holoceno tardío CDM1: a. Punta bifacial, b. Fragmento de punta bifacial. Holoceno Medio: c. Raedera (C3T1), d. Lámina retocada (LM).

Tools. Late Holocene, CDM1. a. Bifacial point, b. Fragment of bifacial point. Middle Holocene. c. Sidescraper (C3T1), d. Retouched blade (LM).

Tabla 5. Frecuencia de artefactos según estadio de reducción. Se contabilizaron productos de talla enteros y fracturados con y sin talón.

Frequency of debitage in each reduction stage. Complete and broken debitage (with and without platform) were taken into account.

\begin{tabular}{|c|c|c|c|c|c|c|c|c|}
\hline \multirow{2}{*}{$\begin{array}{c}\text { Etapa de } \\
\text { producción }\end{array}$} & \multicolumn{2}{|c|}{$\begin{array}{c}\text { Pleistoceno } \\
\text { Final }\end{array}$} & \multicolumn{2}{|c|}{ Temprano } & \multicolumn{2}{|c|}{$\begin{array}{c}\text { Holoceno } \\
\text { Medio }\end{array}$} & \multicolumn{2}{|c|}{ Tardío } \\
\hline & $\mathrm{n}$ & $\%$ & $\mathrm{n}$ & $\%$ & $\mathrm{~N}$ & $\%$ & $\mathrm{n}$ & $\%$ \\
\hline Descortezamento & 0 & 0 & 0 & 0 & 3 & 2,97 & 3 & 1,49 \\
\hline Talla del núcleo & 4 & 50 & 2 & 50 & 42 & 41,58 & 66 & 32,67 \\
\hline Formatización final & 4 & 50 & 2 & 50 & 56 & 55,45 & 133 & 65,84 \\
\hline Total & 8 & 100 & 4 & 100 & 101 & 100 & 202 & 100 \\
\hline
\end{tabular}

los otros momentos, aunque seguidas por piezas de retalla y adelgazamiento bifacial (Figura 6). Seis piezas del Holoceno Medio y cuatro del Tardío fueron generadas durante la reactivación de los filos, indicando que se realizó el mantenimiento de artefactos en los sitios.

Entre los productos de talla enteros los tamaños son muy chicos o chicos en todos los períodos, solo una pieza del Holoceno Tardío es mediana (Figuras 3c y 7). La Tabla 6 muestra que principalmente se obtuvieron lascas, en todos los periodos y en todos los pasos de la secuencia. Durante la talla del núcleo en el Holoceno Medio y Tardío también se generaron laminillas, láminas y lascas largas con porcentajes bajos y muy bajos (Figura 3c y e). Por último, durante la formatización final en estos periodos destacan los porcentajes de laminillas.

Entre el $50 \%$ y el $80 \%$ de los restos por período cuenta con talón. En los conjuntos del Pleistoceno Final se observa diversidad de talones, mientras que para el Holoceno Temprano se hallaron plataformas preparadas y puntiformes. Para el Holoceno Medio y Tardío en referencia a las plataformas producidas durante la formatización final prevalecen talones puntiformes y lineales (Figura 8).

Para evaluar el uso de las piezas se analizaron todos los artefactos formatizados y una muestra de productos de la talla (Tabla 7). Los dos artefactos formatizados del Holoceno Medio presentan huellas de uso probables en base a las evidencias provistas por el análisis funcional (Tabla 8). La raedera presenta pulidos poco reflexivos generalmente opacos y sectores ligeramente brillantes, con distribución extensa sobre el borde de la pieza. También presenta otros indicadores como el redondeamiento del 


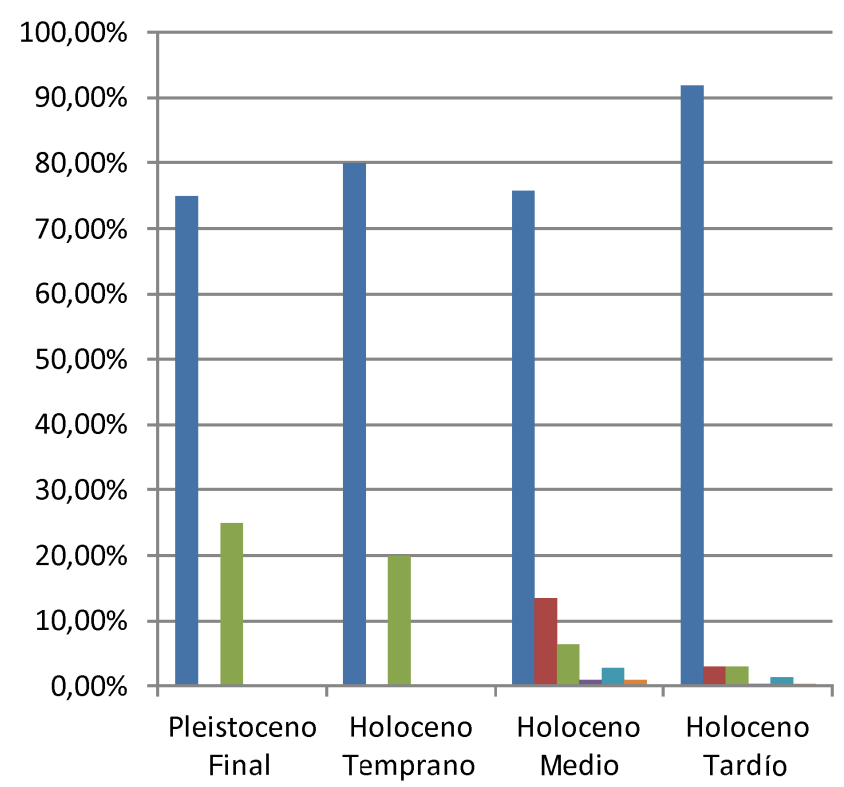

Sin corteza $(0 \%)$

Muyescasa (1-24\%)

Escasa (25-49\%)

Parcial (50-74\%)

Abundante (75-99\%)

Muyabundante (100\%)

Figura 5. Porcentaje de corteza en lascas.

Amount of cortex in flakes.

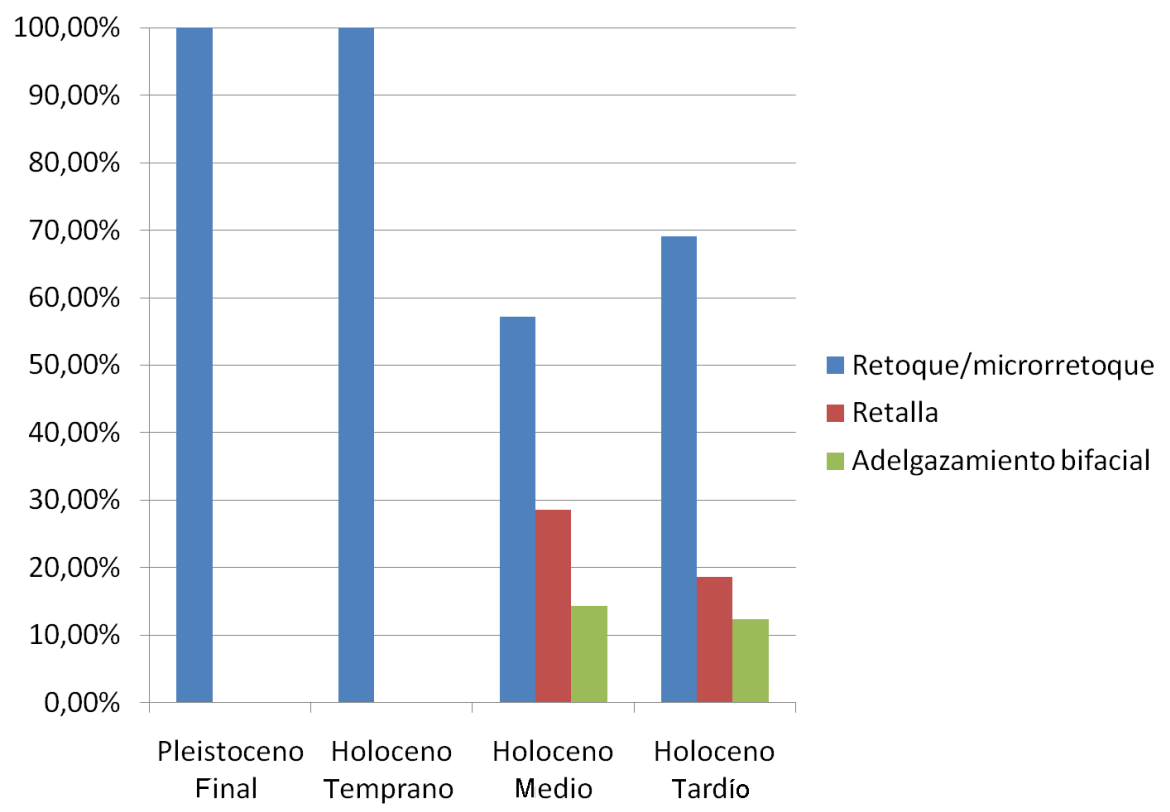

Figura 6. Piezas producidas durante la formatización final. Flakes produced during the final shaping of tools. 


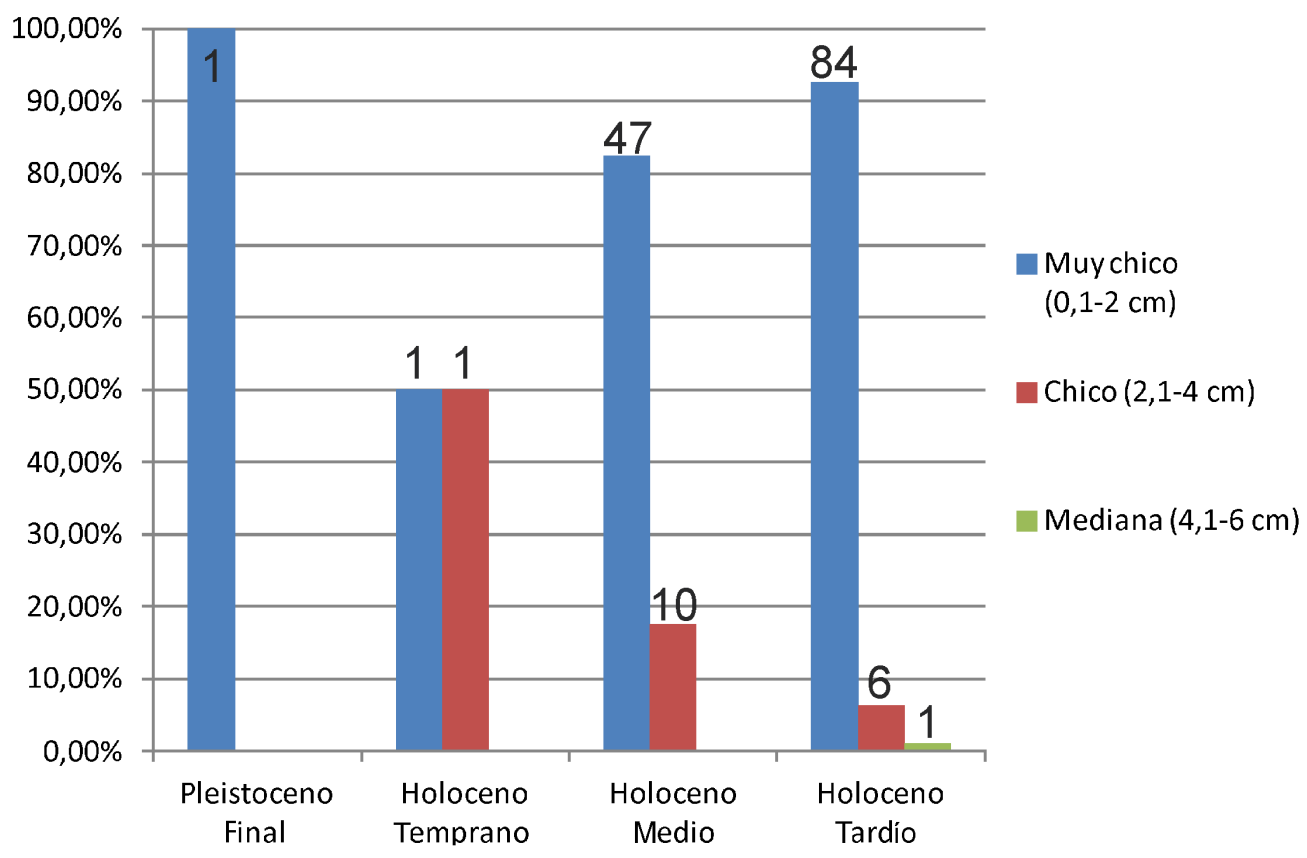

Figura 7. Tamaño de lascas enteras. Size of complete flakes.

Tabla 6. Clases de lascas por etapa de producción. Proportion of flake types in each production stage.

\begin{tabular}{|c|c|c|c|c|c|c|}
\hline Periodo & Etapas de producción & Lascas & Laminillas & Lascas largas & Láminas & Total \\
\hline \multirow{2}{*}{ Pleistoceno Final } & Talla del núcleo & $100 \%$ & $0 \%$ & $0 \%$ & $0 \%$ & $100 \%$ \\
\hline & Formatización final & $100 \%$ & $0 \%$ & $0 \%$ & $0 \%$ & $100 \%$ \\
\hline \multirow{2}{*}{ Holoceno Temprano } & Talla del núcleo & $100 \%$ & $0 \%$ & $0 \%$ & $0 \%$ & $100 \%$ \\
\hline & Formatización final & $50 \%$ & $50 \%$ & $0 \%$ & $0 \%$ & $100 \%$ \\
\hline \multirow{3}{*}{ Holoceno Medio } & Descortezamiento & $100 \%$ & $0 \%$ & $0 \%$ & $0 \%$ & $100 \%$ \\
\hline & Talla del núcleo & $85,71 \%$ & $4,76 \%$ & $2,38 \%$ & $7,14 \%$ & $100 \%$ \\
\hline & Formatización final & $91,07 \%$ & $8,93 \%$ & $0 \%$ & $0 \%$ & $100 \%$ \\
\hline \multirow{3}{*}{ Holoceno Tardío } & Descortezamiento & $100 \%$ & $0 \%$ & $0 \%$ & $0 \%$ & $100 \%$ \\
\hline & Talla del núcleo & $92,42 \%$ & $3,03 \%$ & $1,52 \%$ & $3,03 \%$ & $100 \%$ \\
\hline & Formatización final & $87,22 \%$ & $12,03 \%$ & $0,75 \%$ & $0 \%$ & $100 \%$ \\
\hline
\end{tabular}




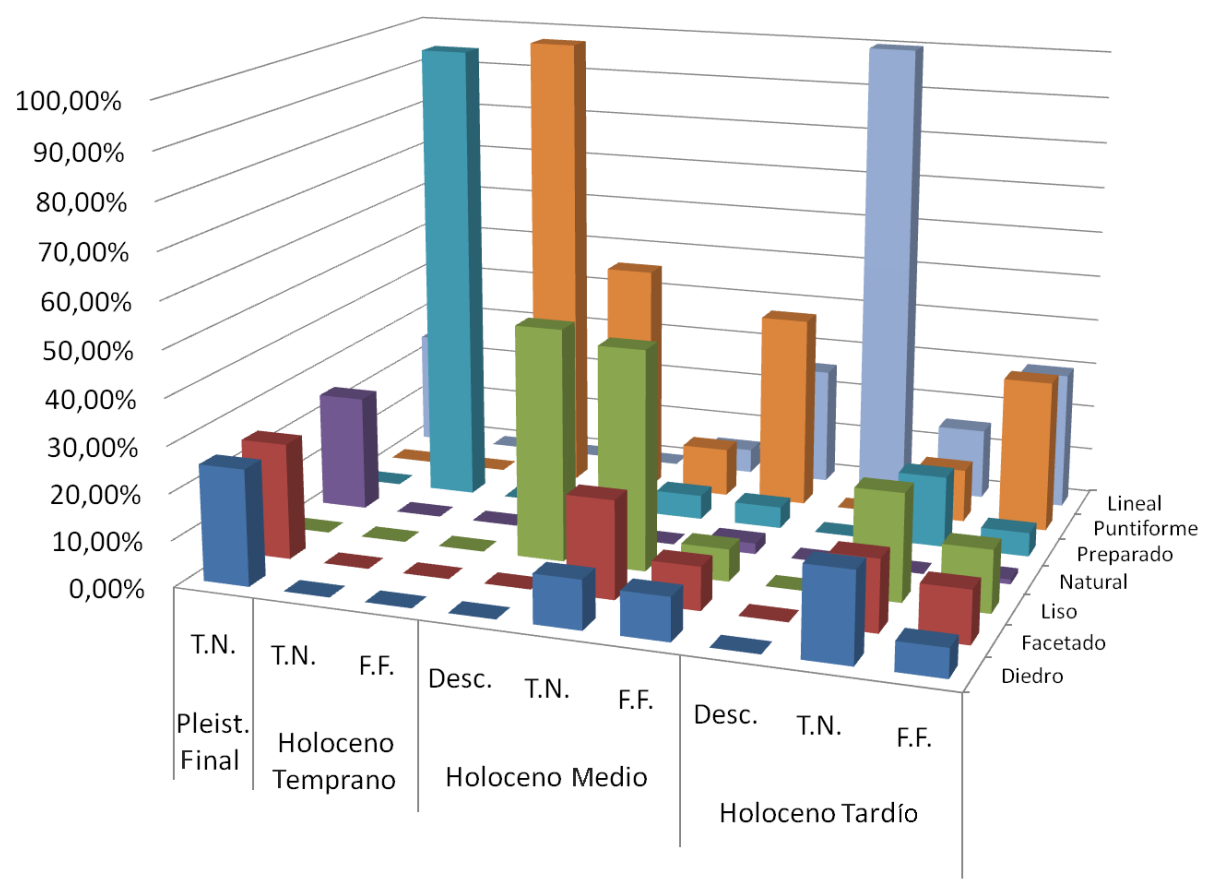

Figura 8. Tipo de talón.

Type of platform.

borde de la pieza y los microesquirlamientos que se asocian a trabajos de cuereado. Para el Holoceno Tardío se identificó una lasca retocada que presenta, sobre el filo, sectores con micropulido irregular y otros de aspecto regular, liso y levemente espeso. Estos últimos poseen una superficie reflexiva clara y muy brillante. Además las huellas alcanzan una extensión marginal desde el borde de la pieza. Estos indicadores sugieren que el artefacto habría sido empleado en el procesamiento de un vegetal leñoso blando mediante movimientos transversales al filo. Estos elementos se vincularían al descortezamiento u otra labor relacionada a la modificación de un leño (Tabla 8; Figura 9). El resto de las piezas no presentan rastros de uso. Las puntas seguramente fueron utilizadas como proyectil, lo cual implica un contacto con baja probabilidad de desarrollar huellas microscópicas.

Con relación a los productos de talla analizados de ambos periodos, cinco lascas y dos láminas, solo se identificaron señales de uso en una lasca del Holoceno Tardío. Esta presenta un micropulido de superficie clara y brillante a modo de banda sobre la arista del borde agudo. Tanto su disposición como la de las estrías asociadas remiten a la ejecución de un movimiento transversal al borde, propio del trabajo de raspado de cuero (Tabla 8; Figura 9).
Con respecto a la procedencia de los artefactos de obsidiana, los resultados del análisis geoquímico por ICP-MS indican que todas las muestras provienen de la fuente Pampa del Asador, reconociéndose restos de las variedades PDA 1 y 2 (Tabla 9, Figura 10).

\section{Discusión: Producción, Uso y Circulación de la Obsidiana en la Meseta}

La circulación de materiales y los modos de interacción entre los grupos requieren el planteo de marcos de referencia, la integración de múltiples líneas de evidencia, la consideración de diferentes

Tabla 7. Muestra de artefactos analizada funcionalmente. AF: artefacto formatizado; XT: producto de talla.

Sample of artifacts with functional analysis. AF: tool. XT: debitage.

\begin{tabular}{|c|c|c|c|c|c|c|}
\hline \multicolumn{2}{|c|}{ Período } & \multirow{2}{*}{$\begin{array}{c}\text { Sitio/nivel } \\
\text { CDM1/1 y } 2\end{array}$} & \multicolumn{2}{|c|}{$\underset{\text { artefactos }}{\mathrm{N}}$} & \multirow{2}{*}{$\begin{array}{c}\mathrm{N} \\
\text { filos } \\
8\end{array}$} & \multirow{2}{*}{$\begin{array}{c}\text { Clase filo } \\
6 \text { retocados } \\
2 \text { naturales }\end{array}$} \\
\hline \multirow{5}{*}{ Holoceno } & Tardío & & 4 & $\mathrm{AF}$ & & \\
\hline & & & 6 & XT & 10 & naturales \\
\hline & \multirow{3}{*}{ Medio } & $\mathrm{LM} / 5$ & 1 & $\mathrm{AF}$ & 2 & $\begin{array}{l}1 \text { retocado; } \\
1 \text { natural }\end{array}$ \\
\hline & & & 1 & XT & 2 & naturales \\
\hline & & C3T1/4 & 1 & $\mathrm{AF}$ & 3 & 3 retocados \\
\hline
\end{tabular}


Tabla 8. Resultado del análisis funcional. SU: sin uso; SG: seguro; PR: probable; TR: transversal; L: longitudinal.

Results of functional analysis. SU: without use: SG: certain; PR: probable; TR. transversal; L: longitudinal.

\begin{tabular}{|c|c|c|c|c|c|c|}
\hline \multicolumn{2}{|c|}{ Período } & Sitio & $\begin{array}{c}\text { Clase AF } \\
\text { o XT }\end{array}$ & Uso & Movimiento & Sustancia \\
\hline \multirow{7}{*}{ Holoceno } & \multirow{5}{*}{ Tardío } & \multirow{5}{*}{ CDM1 } & $\begin{array}{l}\text { Punta } \\
\text { bifacial }\end{array}$ & SU & - & - \\
\hline & & & $\begin{array}{c}\text { Punta } \\
\text { bifacial }\end{array}$ & SU & - & - \\
\hline & & & $\begin{array}{c}\text { Raspador/ } \\
\text { punta } \\
\text { destacada }\end{array}$ & SU & - & - \\
\hline & & & $\begin{array}{l}\text { Lasca } \\
\text { retocada }\end{array}$ & SG & TR & $\begin{array}{l}\text { vegetal } \\
\text { leñoso } \\
\text { blando }\end{array}$ \\
\hline & & & Lasca & SG & TR & cuero \\
\hline & \multirow{2}{*}{ Medio } & $\mathrm{LM}$ & $\begin{array}{l}\text { Lámina } \\
\text { retocada }\end{array}$ & PR & $\mathrm{L}$ & Indet. \\
\hline & & C3T1 & Raedera & PR & $\mathrm{TR}$ & $\begin{array}{l}\text { blanda } \\
\text { (cuero) }\end{array}$ \\
\hline
\end{tabular}

escalas y la articulación entre distintas regiones. Por ello los estudios aquí presentados sobre la obsidiana representan un aporte para la reflexión sobre estas problemáticas. En este sentido las sociedades habrían estructurado la circulación de este recurso por diversos mecanismos hacia la Meseta Central desde PDA, constituyendo esta la única fuente con evidencia de explotación, circulación y uso en este espacio. Los resultados geoquímicos y la evaluación macroscópica obtenidos en este trabajo son congruentes con esta interpretación.

Los conjuntos analizados indican un aumento progresivo de la explotación de la obsidiana a través del tiempo. Su presencia es más recurrente en el Holoceno Temprano y Medio que en el Pleistoceno Final. Durante el Holoceno todos los conjuntos registran artefactos de esta roca, mientras que para el Pleistoceno sólo uno de los cuatro componentes analizados registra esta materia prima. Además, se observa un incremento importante para el Holoceno tardío. En el único componente de este período
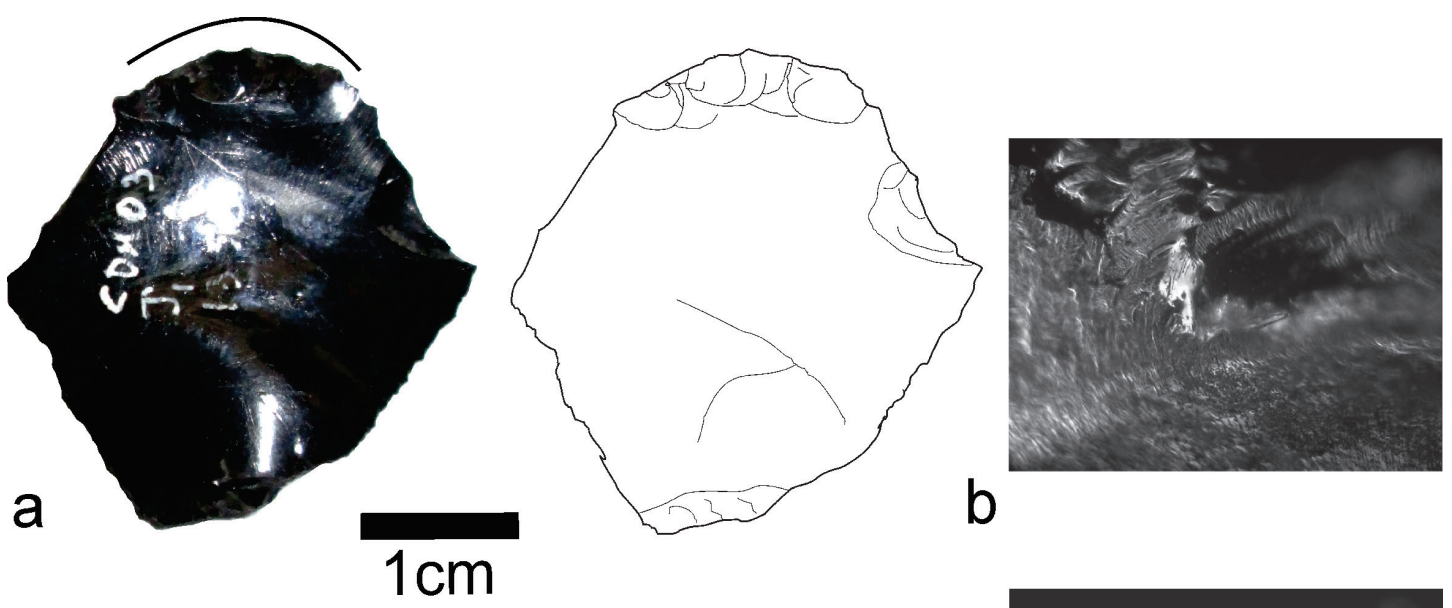

b

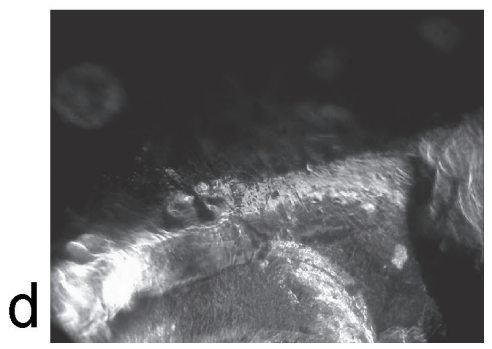

Figura 9. Artefactos con huellas de uso. a. Lasca retocada, CDM1. Dibujo: Manuel Cueto. b. Pulido por acción transversal sobre sustancia vegetal blanda. 150X, c. Lasca, CDM1. d. huellas de raspado de cuero 150X.

Artifacts with use-wear. a. Retouched flake, CDM1. Drawing: Manuel Cueto. $b$. Use-wear produced by a transversal action on a soft vegetable substance. 150X. c. Flake, CDM1. Use-wear of hide scraping activities. 150X. 
Tabla 9. Composición geoquímica de las muestras. CS16: muestra del nivel 5 de C3T1 analizada previamente por Stern, sin datos publicados hasta el momento. s/d: sin datos.

Geochemical composition of the samples. CS16: sample from level 5 of C3T1, previously analyzed by Stern, without published data until now. s/d: without data.

\begin{tabular}{|c|c|c|c|c|c|c|c|c|c|c|c|c|c|c|c|c|}
\hline Muestra & CS01 & $\mathrm{CS} 02$ & $\mathrm{CS} 03$ & CS04 & CS05 & CS06 & CS07 & CS08 & CS09 & CS10 & CS11 & $\mathrm{CS} 12$ & CS13 & CS14 & CS15 & CS16 \\
\hline Fuente & PDA1 & PDA1 & PDA1 & PDA1 & PDA1 & PDA2 & PDA1 & PDA1 & PDA2 & PDA2 & PDA1 & PDA2 & PDA1 & PDA1 & PDA2 & PDA2 \\
\hline $\mathrm{Ti}^{*}$ & 945 & 909 & 931 & 934 & 1007 & 790 & 888 & 879 & 828 & 766 & 904 & 810 & 909 & 897 & 778 & $\mathrm{~s} / \mathrm{d}$ \\
\hline $\mathrm{Mn}$ & 283 & 270 & 277 & 265 & 269 & 209 & 268 & 266 & 209 & 206 & 268 & 213 & 267 & 266 & 217 & $\mathrm{~s} / \mathrm{d}$ \\
\hline $\mathrm{Rb}$ & 202 & 203 & 205 & 198 & 197 & 245 & 201 & 200 & 240 & 234 & 205 & 246 & 202 & 202 & 225 & 239 \\
\hline $\mathrm{Sr}$ & 29 & 29 & 29 & 28 & 28 & 5 & 28 & 28 & 6 & 4 & 30 & 6 & 28 & 29 & 8 & $<5$ \\
\hline $\mathrm{Y}$ & 33 & 33 & 33 & 32 & 32 & 46 & 32 & 32 & 47 & 46 & 33 & 48 & 32 & 33 & 43 & $\mathrm{~s} / \mathrm{d}$ \\
\hline $\mathrm{Zr}$ & 132 & 133 & 134 & 129 & 131 & 146 & 132 & 131 & 145 & 139 & 133 & 146 & 132 & 132 & 151 & 136 \\
\hline $\mathrm{Nb}$ & 25 & 25 & 27 & 24 & 27 & 28 & 27 & 25 & 33 & 32 & 25 & 33 & 26 & 25 & 36 & 31 \\
\hline Cs & 10,7 & 10,7 & 10,9 & 10,5 & 10,5 & 13,5 & 10,7 & 10,6 & 13,4 & 13,0 & 10,8 & 13,6 & 10,7 & 10,9 & 12,2 & $\mathrm{~s} / \mathrm{d}$ \\
\hline $\mathrm{Ba}$ & 253 & 247 & 250 & 241 & 245 & 10 & 247 & 246 & 11 & 10 & 246 & 11 & 249 & 250 & 10 & $<10$ \\
\hline $\mathrm{Hf}$ & 5,1 & 4,9 & 5,0 & 4,8 & 4,8 & 6,7 & 5,3 & 5,0 & 6,6 & 6,3 & 5,1 & 6,6 & 5,1 & 5,2 & 9,5 & $\mathrm{~s} / \mathrm{d}$ \\
\hline $\mathrm{Pb}$ & 22,3 & 22,3 & 22,3 & 22 & 23,1 & 24,4 & 23,7 & 22,5 & 25,2 & 24,5 & 22,8 & 25,4 & 22,9 & 22,8 & 23,9 & $\mathrm{~s} / \mathrm{d}$ \\
\hline Th & 19,7 & 20,0 & 20,0 & 19,6 & 19,9 & 20,3 & 20,1 & 20,1 & 20,4 & 20,1 & 20,0 & 20,6 & 20,0 & 20,0 & 20,1 & $\mathrm{~s} / \mathrm{d}$ \\
\hline $\mathrm{U}$ & 5,5 & 5,3 & 5,5 & 5,2 & 5,5 & 6,3 & 5,3 & 5,4 & 6,4 & 6,2 & 5,3 & 6,4 & 5,5 & 5,5 & 5,9 & $\mathrm{~s} / \mathrm{d}$ \\
\hline $\mathrm{La}$ & 37,9 & 38,2 & 39,3 & 38,1 & 38,1 & 22,4 & 38,6 & 38,0 & 22,8 & 22,3 & 37,6 & 23,0 & 38,8 & 38,7 & 27,8 & $\mathrm{~s} / \mathrm{d}$ \\
\hline $\mathrm{Ce}$ & 76,8 & 77 & 78,8 & 77,4 & 78,8 & 53,7 & 79,2 & 77,9 & 56,5 & 53,7 & 76,6 & 55,2 & 79,1 & 79,5 & 65,5 & $\mathrm{~s} / \mathrm{d}$ \\
\hline $\operatorname{Pr}$ & 8,41 & 8,33 & 8,55 & 8,45 & 8,48 & 6,91 & 8,56 & 8,39 & 6,97 & 6,73 & 8,27 & 6,97 & 8,68 & 8,58 & 7,95 & $\mathrm{~s} / \mathrm{d}$ \\
\hline $\mathrm{Nd}$ & 31,8 & 31,8 & 33,0 & 31,1 & 30,6 & 28,6 & 31,7 & 31,7 & 27,9 & 27,7 & 31,4 & 29,7 & 33,2 & 32,1 & 30,8 & $\mathrm{~s} / \mathrm{d}$ \\
\hline $\mathrm{Sm}$ & 6,6 & 6,88 & 6,98 & 7,08 & 6,91 & 7,80 & 7,08 & 7,04 & 7,58 & 7,31 & 6,80 & 7,71 & 7,20 & 7,01 & 7,65 & $\mathrm{~s} / \mathrm{d}$ \\
\hline $\mathrm{Eu}$ & 0,54 & 0,53 & 0,64 & 0,56 & 0,57 & DL & 0,61 & 0,56 & DL & DL & 0,52 & DL & 0,60 & 0,58 & 0,15 & $\mathrm{~s} / \mathrm{d}$ \\
\hline $\mathrm{Gd}$ & 10,2 & 10,7 & 10,7 & 10,4 & 10,6 & 11,5 & 10,9 & 10,6 & 11,7 & 11,2 & 10,5 & 11,4 & 11,1 & 11,1 & 11,9 & $\mathrm{~s} / \mathrm{d}$ \\
\hline $\mathrm{Tb}$ & 1,20 & 1,18 & 1,15 & 1,15 & 1,13 & 1,51 & 1,17 & 1,19 & 1,54 & 1,50 & 1,13 & 1,56 & 1,25 & 1,21 & 1,51 & $\mathrm{~s} / \mathrm{d}$ \\
\hline Dv & 6,33 & 6,14 & 6,46 & 6,00 & 6,24 & 8,99 & 6,3 & 6,35 & 8,65 & 8,44 & 6,35 & 8,78 & 6,38 & 6,42 & 8,35 & $\mathrm{~s} / \mathrm{d}$ \\
\hline Ho & 1,13 & 1,12 & 1,12 & 1,06 & 1,14 & 1,71 & 1,14 & 1,13 & 1,66 & 1,64 & 1,17 & 1,77 & 1,13 & 1,17 & 1,57 & $\mathrm{~s} / \mathrm{d}$ \\
\hline $\mathrm{Er}$ & 3,80 & 3,70 & 3,80 & 3,63 & 3,63 & 5,22 & 3,61 & 3,73 & 5,17 & 4,99 & 3,87 & 5,40 & 3,83 & 3,70 & 4,85 & $\mathrm{~s} / \mathrm{d}$ \\
\hline $\mathrm{Tm}$ & 0,42 & 0,40 & 0,40 & 0,37 & 0,40 & 0,61 & 0,41 & 0,39 & 0,62 & 0,62 & 0,39 & 0,64 & 0,43 & 0,42 & 0,59 & $\mathrm{~s} / \mathrm{d}$ \\
\hline $\mathrm{Yb}$ & 3,37 & 3,23 & 3,32 & 3,17 & 3,24 & 4,83 & 3,32 & 3,28 & 4,97 & 4,74 & 3,24 & 4,83 & 3,49 & 3,42 & 4,42 & $\mathrm{~s} / \mathrm{d}$ \\
\hline $\mathrm{Lu}$ & 0,38 & 0,40 & 0,37 & 0,36 & 0,38 & 0,59 & 0,39 & 0,4 & 0,59 & 0,57 & 0,40 & 0,60 & 0,40 & 0,40 & 0,57 & $\mathrm{~s} / \mathrm{d}$ \\
\hline
\end{tabular}

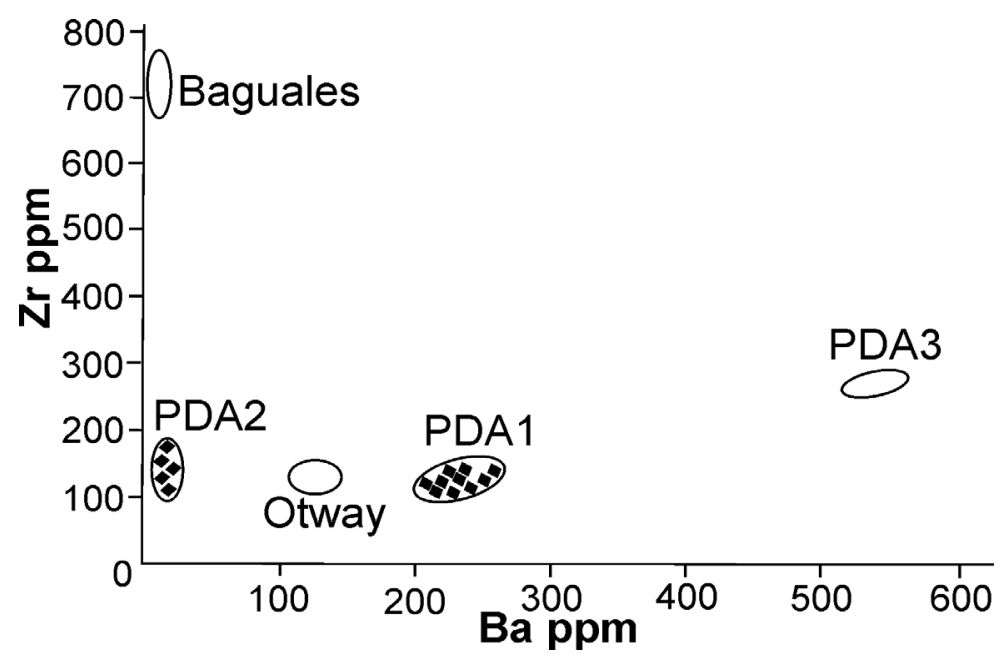

Figura 10. Perfil geoquímico Ba vs. Zr según partes-por-millón (ppm) de la muestra analizada comparado con distintas fuentes. Ba vs. Zr geochemical profile in parts-per-millon (ppm) of the analyzed samples, compared to different sources. 
el porcentaje de obsidiana podría evidenciar un contexto de mayor explotación.

Las evidencias paraelPleistocenoFinal/Holoceno Temprano son escasas local y regionalmente (Aguerre 2003; Cardich y Flegenheimer 1978; Durán et al. 2003; Franco et al. 2010), indicando que esta materia prima no habría jugado un rol relevante en la organización tecnológica de estas sociedades. En los conjuntos de La María y Cerro Tres Tetas de ambos períodos hay únicamente productos de la talla pequeños y muy pequeños, principalmente producto de la formatización final de artefactos. Esto podría indicar el ingreso a los sitios de instrumentos terminados o en avanzado estado de formatización. En concordancia, a nivel regional se recuperaron puntas de proyectil de obsidiana para las cuales se propuso un ingreso a los sitios ya manufacturadas y por intercambio (Aguerre 2003; Cardich y Flegenheimer 1978; Hermo y Miotti 2010). Cabe destacar que en este sector las prácticas de explotación de rocas silíceas (Cueto 2015; Frank 2011; Skarbun 2011) señalan el predominio de las actividades de formatización final en sitios reparados. Queda por dilucidar si, en el caso de la obsidiana se trata del traslado de estos artefactos desde sectores cercanos a la fuente o si estamos ante evidencias de una estructuración local del espacio. Esta podría caracterizarse por el ingreso a las localidades de nódulos o núcleos de obsidiana que fueron trabajados en diversos espacios hasta el ingreso al sitio en estados avanzados de formatización.

En el Holoceno Medio, si bien la proporción continua siendo baja, en los sitios analizados aumenta respecto a periodos anteriores evidenciando un mayor trabajo con esta roca. Este rasgo, y las características de las secuencias de manufactura, concuerdan con las tendencias de la meseta (Crivelli Montero 1976-1980; Hermo 2008; Hermo y Miotti 2010). Ello se produce en un contexto asociado a un aumento demográfico (Hermo 2008; Miotti 2006) y que evidencia mayor actividad de producción lítica. Las secuencias se caracterizan por la realización de las etapas finales en los sitios e incluyen actividades de descortezamiento. En este sentido la presencia de corteza es mayor que para el resto de los períodos indicando el ingreso de nódulos o núcleos. Dado que las lascas de descortezamiento y reducción del núcleo son de tamaño chico y muy chico inferimos que las rocas ingresadas eran pequeñas o medianas. Durante la generación de soportes se produjo un conjunto significativo de artefactos de módulo laminar (láminas, laminillas y lascas largas) de manera semejante a aquellos producidos en la meseta con otras litologías (Castro 1994; Crivelli
Montero 1976-1980; Durán 1986-1987; Hermo 2008; Paunero et al. 2007).

La evidencia señala que las tareas de formatización final incluyeron regularización marginal de los bordes y secundariamente retalla, adelgazamiento bifacial y reactivación de filos. Estas actividades implicarían mayor trabajo en las etapas finales de manufactura respecto a periodos cronológicos previos. Ello concuerda con los patrones de regularización de filos seguidos con rocas silíceas en los mismos sitios (Frank 2016; Iparraguirre y Cueto 2015; Paunero et al. 2007; Skarbun 2009, 2011). En tanto, la abundancia de laminillas entre los productos de formatización final y la elevada proporción de talones puntiformes y lineales indicarían el empleo de la técnica de presión, más intensamente que lo registrado para recursos locales (Skarbun 2011). Mediante estos procedimientos se manufacturaron al menos dos instrumentos de obsidiana procedentes de dos de las cuatro ocupaciones del Holoceno Medio. Esto ocurre en un período donde aumenta en los conjuntos la frecuencia de artefactos formatizados producidos y/o descartados respecto a momentos previos. En este sentido, probablemente la cantidad de artefactos formatizados en obsidiana hallados hasta el momento en los sitios no refleje fielmente la totalidad de artefactos producidos en esta litología. Consideramos que aquellos fabricados o reavivados en los sitios podrían haber sido trasladados a otros espacios. Entre los artefactos usados podrían considerarse los productos de talla sin formatización como rasgo distintivo de esta materia prima (Hermo y Miotti 2010). Sin embargo, el análisis funcional no evidencia el uso de productos de talla para este momento. Cabe aclarar que dicho tratamiento para la obsidiana, en caso de haberse concretado, no revestiría un rasgo distintivo sino una similitud en cuanto al empleo de bordes naturales de rocas locales (Castro 1994; Paunero et al. 2007). Con los artefactos formatizados se realizaron cinemáticas diversas y se procesó una única sustancia, el cuero. Los resultados alcanzados señalan una similitud entre el consumo de esta roca y el de litologías disponibles en La María y Cerro Tres Tetas (Cueto 2015).

En el Holoceno Tardío hay mayor representación de obsidiana. Los altos porcentajes de productos de talla sin cortex indicarían que hubo escasa actividad de descortezamiento dentro de los sitios. Sin embargo, al igual que en el período anterior esta roca habría circulado hacia la meseta como nódulo o núcleo, teniendo en ocasiones restos de corteza. Las masas de roca ingresadas serían en su mayoría de tamaño chico. Aunque, considerando 
la presencia de una lasca y un instrumento medianos, también habrían entrado elementos más grandes. En este sentido existen similitudes con los conjuntos de Costa Norte respecto a la dimensión de las masas de roca (Ambrústolo et al. 2012). La información sobre dicho espacio y los resultados geoquímicos aquí presentados sobre una lasca de descortezamiento del sitio El Rincón, indican que la práctica de traslado de nódulos o núcleos desde PDA se extendió, para este período, hasta la costa atlántica.

Las tareas registradas durante la producción artefactual se vinculan con la obtención de formas bases y predominantemente con la formatización final. Durante la producción de soportes en CDM1 se generaron principalmente lascas y en menor medida piezas de módulo laminar. Estos últimos decrecen en $50 \%$ respecto al Holoceno Medio. Por otra parte los diferentes productos de talla presentan proporciones similares en comparación con recursos locales (Skarbun 2011). Al igual que en el Holoceno Medio hay evidencias que remiten al empleo de la técnica de presión, implicando una diferencia entre la gestión de la obsidiana y las rocas locales (Skarbun 2011).

La producción artefactual sigue la tendencia regional dado que se hallaron puntas de proyectil, raspadores y lascas retocadas, a su vez se emplearon artefactos sin formatización secundaria. Con los instrumentos se realizó un mismo tipo de acción, procesándose diversas sustancias: vegetales y cuero. Estos resultados no remiten a un uso específico de esta roca. El uso del borde natural de una lasca constituye una diferencia con el período previo. Sin embargo esta única evidencia no sería significativa para valorarla como rasgo distintivo de esta materia prima; tampoco se registraron huellas en láminas. Las puntas habrían sido empleadas como proyectiles. Aunque en CDM1 solo se recuperaron de obsidiana, ello no implicaría la preferencia de esta roca para su formatización. Nuestros registros en sitios superficiales en la localidad muestran abundantes puntas en litologías inmediatamente disponibles (Paunero et al. 2010).

En síntesis, las prácticas de gestión desarrolladas con la obsidiana en La María y Cerro Tres Tetas diferirían a través del tiempo, distinguiéndose dos momentos. El primero involucra las ocupaciones del Pleistoceno Final y el Holoceno Temprano, en el cual se explotó esta roca de manera escasa, con un rol poco relevante en la organización tecnológica, donde probablemente los artefactos ingresaron a los sitios ya manufacturados. Consideramos preliminarmente que el abastecimiento por parte de los grupos que ocuparon este sector de la meseta se habría efectuado por intercambio y en baja frecuencia o de modo eventual en el marco de los circuitos de movilidad.
El segundo momento abarca las ocupaciones del Holoceno Medio y Tardío, donde se registra una tendencia hacia el incremento en la explotación de esta roca. Las estrategias de manufactura y consumo concuerdan en general con las implementadas para litologías silíceas. Puede considerarse que su gestión se incorporaba a los procesos cotidianos de manufactura de herramientas y procesamiento de recursos, implicando conocimientos y modos de producción socialmente compartidos. Si bien es evidente que estas sociedades conocían las cualidades de la obsidiana para la talla, habitaban un paisaje con una gran disponibilidad de rocas de excelente calidad. Por ello, no poseemos evidencias que nos permitan inferir que hubo una mayor valorización de esta roca por sobre aquellas inmediatamente disponibles. Por otro lado, aunque no se observa un tratamiento diferencial destacable, se distingue a nivel de las estrategias de abastecimiento. El hecho de que los registros de obsidiana en la meseta sean inferiores al de las rocas locales no anula la posibilidad que esta materia prima haya sido obtenida por intercambio, ni el conocimiento que se tenía sobre su localización. Las secuencias de producción para este segundo momento son más completas y la evidencia indica que se realizaron de forma más frecuente. Por esta razón no compartimos que los artefactos hayan sido descartados como resultado de una gestión eventual de la roca. En este sentido la obsidiana probablemente se obtuvo en el marco de los circuitos de movimiento temporales/ anuales. Las elevadas proporciones de esta roca nos permiten suponer un mayor vínculo y fluidez en las redes sociales establecidas con grupos que habitaban otros puntos del espacio, incluso aquellos más cercanos al área de disponibilidad natural de PDA. Las redes de comunicación que posibilitaron el abastecimiento de esta roca probablemente se estructuraron en torno al intercambio de otros bienes o recursos (con sentido de circulación oesteeste [cordillera-meseta-costa] y viceversa) como a instancias de reunión que necesariamente refuerzan los lazos sociales entre los grupos. Asimismo consideramos que el abastecimiento en ocasiones, con menor frecuencia, pudo producirse por la colecta directa en la fuente y el transporte de la roca hacia la meseta por parte de un mismo grupo. Ambas alternativas no son contradictorias.

Finalmente, un elemento que surge y debemos considerar es la necesidad de profundizar estudios a escala interregional entre equipos que desarrollan investigaciones en el sector cordillerano y la meseta en pos de evaluar con mayor detalle los modos de abastecimiento, circulación y gestión de la obsidiana y de otros recursos y aportar más 
cantidad de elementos que nos permitan comprender los modos de interacción entre grupos humanos que habitaron distintas geografías.

Agradecimientos: Quisiéramos agradecer a Rafael Paunero, director de nuestro proyecto de investigación y demás miembros del equipo. Charles Stern realizó la interpretación de los datos geoquímicos. A dos evaluadores anónimos por sus valiosos comentarios. Este trabajo fue realizado gracias al apoyo de CONICET y la UNLP.

\section{Referencias Citadas}

Aguerre, A.M. 2003. La Martita: ocupaciones de 8000 años en la Cueva 4. En Arqueología y Paleoambiente en la Patagonia Santacruceña Argentina, editado por A.M. Aguerre, pp. 29-61. Nuevo Offset, Buenos Aires.

Ambrústolo, P., M.A. Zubimendi y C. Stern 2012. Explotación de obsidiana negra en la costa norte de Santa Cruz (Patagonia argentina). Cazadores Recolectores del Cono Sur 6:77-86.

Andrefsky, W. 2005. Lithics. Macroscopic Approach to Analysis. 2nd Edition, Cambridge University Press, New York.

Aschero, C. 1975. Ensayo para una clasificación morfológica de artefactos líticos aplicada a estudios tipológicos comparativos. Manuscrito en posesión del autor.

Bate, F. 2014. ¿Tehuelches y Chonos? Sobre la apertura de las relaciones comunales. En Propuestas para la Arqueología, Volumen 1, pp. 139-186. Colección Nuestros Clásicos. Escuela Nacional de Antropología e Historia, Mexico D.F.

Belardi, J.B., P. Tiberi, C.R. Stern y A. Súnico 2006. Al este del cerro Pampa: ampliación del área de disponibilidad de obsidiana de Pampa del Asador (Provincia de Santa Cruz). Intersecciones en Antropología 7:27-36.

Borrero, L.A. 2001. Cambios, continuidades, discontinuidades: discusiones sobre arqueología Fuego-patagónica. En Historia Argentina Prehispánica, editado por E. Berberián y A. Nielsen, pp. 815-838. Editorial Brujas, Córdoba.

Cardich, A. y N. Flegenheimer 1978. Descripción y tipología de las industrias más antiguas de Los Toldos. Relaciones de la Sociedad Argentina de Antropología. Nueva Serie XII:225-242.

Cardich, A., E. Mansur-Franchomme, V. Durán y M. Giesso 1981-82. Arqueología de las cuevas de El Ceibo, Provincia de Santa Cruz, Argentina. Relaciones de la Sociedad Argentina de Antropología XIV:241-267.

Cardich, A., R.S. Paunero y A.S. Castro 1993-1994. Análisis de los conjuntos líticos de la Cueva 2 de Los Toldos (Santa Cruz, Argentina). Anales del Instituto de la Patagonia. Serie Ciencias Humanas 22:149-173.

Castro, A.S. 1994. El Análisis Funcional de Materiales Líticos por Medio de la Observación Microscópica de Huellas de Uso: Un Modelo Alternativo de Clasificación Tipológica. Tesis doctoral, Facultad de Ciencias Naturales y Museo, Universidad Nacional de La Plata, La Plata.

Civalero, M.T. 1999. Obsidiana en Santa Cruz, una problemática a resolver. En Soplando en el viento... Actas de las Terceras Jornadas de Arqueología de la Patagonia, editado por R. Goñi, pp. 155-164. Instituto Nacional de Antropología y Pensamiento Latinoamericano y Universidad Nacional del Comahue, Neuquén-Buenos Aires.

Collins, S. 1989-90. Una propuesta conductual para el estudio de la arqueología lítica. Etnía 34-35:47-65.
Crivelli Montero, E. 1976-1980. La industria Casapedrense (Colección Menghin). Runa XIII (1-2):35-57.

Cueto, M.E. 2015. Análisis de los Procesos de Uso de Artefactos Líticos en Sociedades Cazadoras-Recolectoras. Ocupaciones Correspondientes a La Transición Pleistoceno/Holoceno, Meseta Central de Santa Cruz. Archaeopress. Publish of British Archaeological Reports, Oxford.

Cueto, M.E. y A.D. Frank 2008-2010. Prueba experimental del trabajo del hueso con herramientas líticas. Tratamiento térmico y manifestación de trazas de uso. Patagonia, Argentina. Boletín de Arqueología Experimental 8:13-23.

Cueto, M.E., R.S. Paunero y A.S. Castro 2012. La aplicación del análisis funcional sobre el conjunto artefactual lítico del componente temprano del sitio Casa del Minero 1 para la determinación de operaciones técnicas. Actas del XVIII Congreso Nacional de Arqueología Chilena, pp. 519-531. Sociedad Chilena de Arqueología, Santiago.

Cueto, M.E., F. Skarbun y A.D. Frank 2014. Tecnología lítica de los cazadores-recolectores de la meseta central patagónica. Balances y perspectivas para una propuesta de integración. En Indústrias líticas na América do Sul: Abordagens Teóricas e Metodológicas, editado por A. Lourdeau, S.A. Viana y M.J. Rodet, pp. 173-202. EdUFPE, Recife.

Durán, V. 1987. Estudio tecno-tipológico de los raspadores del sitio El Verano-Cueva 1. Patagonia Centro Meridional, Santa Cruz, Argentina. Anales de Arqueología y Etnología 41/42:129-163.

Durán, V., A. Gil, G. Neme y A. Gasco 2003. El Verano: ocupaciones de 8900 años en la Cueva 1 (Santa Cruz, Argentina). En Arqueología y Paleoambiente en la Patagonia Santacruceña Argentina, editado por A.M. Aguerre, pp. 93-120. Nuevo Offset, Buenos Aires.

Espinosa, S.L. y R. Goñi 1999. ¡Viven!: una fuente de obsidiana en la provincia de Santa Cruz. Soplando en el Viento... Actas de las Terceras Jornadas de Arqueología de la Patagonia, pp 177-188. Instituto Nacional de Antropología y Pensamiento Latinoamericano y Universidad Nacional del Comahue, NeuquénBuenos Aires.

Fernández, M.V. y P. Leal 2014. Determining the provenance of obsidian in southern patagonia using optical properties. Archaeometry $56: 1-18$

Fernández, M.V., C.R. Stern y P.R. Leal 2015. Geochemical analysis of obsidian from archaeological sites in northwestern Santa Cruz Province, Argentine Patagonia. Quaternary International 375:44-54.

Franco, N.V., M. Martucci,P.Ambrústolo, G. Brook, M.V. Mancini y N. Cirigliano 2010. Ocupaciones humanas correspondientes a la transición Pleistoceno-Holoceno al sur del macizo del deseado: el área de La Gruta (provincia de Santa Cruz, Argentina). Relaciones de la Sociedad Argentina de Antropología XXXV:301-308. 
Frank, A.D. 2011. Tratamiento Térmico y Manejo del Fuego en Sociedades Cazadoras-Recolectoras de la Meseta Central de Santa Cruz. Tesis doctoral, Facultad de Ciencias Naturales y Museo, Universidad Nacional de La Plata, La Plata.

Frank, A.D. 2016. Tratamiento térmico de artefactos líticos en Cerro Tres Tetas 1, meseta central de Santa Cruz, Patagonia Argentina. En Arqueología de la Patagonia: de Mar a Mar, editado por F. Mena, pp. 367-378. Ediciones CIEP y Nire Negro, Coyhaique.

García-Herbst, A., C. Stern, H. Neff, J.L. Lanata y L. García Albarido 2007. Laser ablation icp-ms analysis of black obsidian nodules from Pampa del Asador and archaeological samples from Southernmost Patagonia (Santa Cruz Province). En Arqueología de Fuego-Patagonia. Levantando Piedras, Desenterrando Huesos... y Develando Arcanos, editado por F. Morello, M. Martinic, A. Prieto y G. Bahamonde, pp. 235-246. Centro de Estudios del Cuaternario Antártico (CEQUA), Punta Arenas.

Gómez Otero, J. y C. Stern 2005. Circulación, intercambio y uso de obsidianas en la costa de la provincia del Chubut (Patagonia argentina), durante el Holoceno tardío. Intersecciones en Antropología 6:93-108.

Hermo, D. 2008. Los Cambios en la Circulación de las Materias Primas Líticas en Ambientes Mesetarios de Patagonia. Una Aproximación para la Construcción de los Paisajes Arqueológicos de las Sociedades Cazadoras-Recolectoras. Tesis doctoral, Facultad de Ciencias Naturales y Museo, Universidad Nacional de La Plata, La Plata.

Hermo, D. y L.L. Miotti 2010. La obsidiana en el Nesocratón del Deseado (Santa Cruz, Argentina): extractos de una oscura biografía. En Biografías de Paisajes y Seres. Visiones desde la Arqueología Sudamericana, editado por D. Hermo y L. Miotti, pp. 111-132. Encuentro Grupo Editor, Córdoba.

Iparraguirre, A. y M. Cueto 2015. Análisis de la tecnología lítica del Holoceno Medio en Cerro Tres Tetas, Cueva 1, Meseta Central de Santa Cruz, Argentina. Libro de resúmenes. XIV Congreso Nacional de Estudiantes de Arqueología. Arqueologías y Redes, p. 44. Facultad de Filosofía y Humanidades, Universidad Nacional de Córdoba.

Mansur-Franchomme, M.E. 1984. Préhistoire de Patagonie: l'industrie "Nivel 11" de la Province de Santa Cruz (Argentine). Technologie Lithique et Traces d'Utilisation. British Archaeological Reports, Oxford.

Meltzer, D. 1989. Was stone exchanged among eastern North American paleoindians? En Eastern Paleoindian Lithic Resource Use, editado por C.J. Ellis y J. Lothrop, pp. 11-39. Westview Press, Boulder.

Miotti, L.L. 2006. Paisajes domésticos y sagrados desde la arqueología de los cazadores-recolectores en el Macizo del Deseado, Provincia de Santa Cruz. Cazadores Recolectores del Cono Sur. Revista de Arqueología 1:11-40.

Miotti, L.L. y M.C. Salemme 2004. Poblamiento, movilidad y territorios entre las sociedades cazadoras-recolectoras de Patagonia. Complutum 15:177-206.

Musters, G. 2005. Vida entre los Patagones. El Elefante Blanco, Buenos Aires.

Nacuzzi, L. 2007. Los grupos nómades de la Patagonia y el Chaco en el siglo XVIII: Identidades, espacios, movimientos y recursos económicos ante la situación de contacto. Una reflexión comparativa. Chungara Revista de Antropología Chilena 39:221-234.
Nami, H.G. 1992. El subsistema tecnológico de la confección de instrumentos líticos y la explotación de los recursos del ambiente: una nueva vía de aproximación. Shincal 2:13-53.

Newlander, K. 2012. Exchange, Embedded Procurement, and Hunter-Gatherer Mobility: A Case Study from the North American Great Basin. Tesis Doctoral, University of Michigan, Michigan.

Onelli, C. 1904. Trepando los Andes. Compañía Sud-Americana de Billetes de Banco, Buenos Aires.

Pallo, M.C. y L.A. Borrero 2015. ¿Intercambio o movilidad?: Una evaluación sobre el uso de escalas de análisis espaciales y curvas de declinación en patagonia centro-meridional (Argentina). Latin American Antiquity 26:287-303.

Paunero, R.S. 1993-94. El sitio Cueva 1 de la Localidad Arqueológica Cerro Tres Tetas (Ea San Rafael, Santa Cruz, Argentina). Anales de Arqueología y Etnología 48/49:73-90.

Paunero, R.S. 2000. Localidad Arqueológica La María. En Guía de Campo de la Visita a las Localidades Arqueológicas: La Colonización del Sur de América Durante la Transición Pleistoceno/Holoceno, editado por L.L. Miotti, R.S. Paunero, M.C. Salemme y G.R. Cattáneo, pp. Edición Nacional, La Plata.

Paunero, R.S. 2009. La colonización humana de la meseta central de Santa Cruz durante el Pleistoceno final: indicadores arqueológicos, referentes estratigráficos y nuevas evidencias. En Arqueología de Patagonia: una Mirada desde el Último Confín, editado por M.C. Salemme, F. Santiago, M. Álvarez, E. Piana, M. Vazquez y M.E. Mansur, pp. 85-100. Editorial Utopías, Ushuaia.

Paunero, R.S. y A.S. Castro 2001. Análisis lítico y funcionalidad del componente inferior de Sitio Cueva 1, Localidad Arqueológica Cerro Tres Tetas, Provincia de Santa Cruz, Argentina. Punta Arenas. Chile. Anales del Instituto de la Patagonia. Serie Ciencias Humanas 29:189-206.

Paunero, R.S., A.S. Castro y M. Reyes 2007. Estudios líticos del componente medio del Sitio Cueva 1 de Cerro Tres Tetas, Santa Cruz, Argentina: Implicaciones para construir patrones de distribución artefactual y uso del microespacio. En Arqueología de Fuego Patagonia. Levantando Piedras, Desenterrando Huesos...y Develando Arcanos, editado por F. Morello, M. Martinic, A. Prieto y G. Bahamonde, pp. 613-622. Centro de Estudios del Cuaternario Antártico (CEQUA), Punta Arenas.

Paunero, R.S., A.D. Frank, C. De Feo, N. Lunazzi, D. Ramos y C. Valiza Davis 2010. Sitios a cielo abierto en la Meseta Central de Santa Cruz: metodología y resultados en perspectiva regional. Libro de resúmenes del XVII Congreso Nacional de Arqueologia Argentina, pp.?. Universidad Nacional de Cuyo. Mendoza.

Paunero, R.S., A.D. Frank, F. Skarbun, G. Rosales, G. Zapata, M.E. Cueto, M.F. Paunero, D.G. Martinez, R. López, N. Lunazzi y M. Del Giorgio 2005. Arte rupestre en estancia La María, Meseta Central de Santa Cruz: Sectorización y contextos arqueológicos. Relaciones de la Sociedad Argentina de Antropología XXX:147168.

Renfrew, C. 1977. Alternative models for exchange and spatial distribution. En Exchange Systems in Prehistory, editado por T. Earle y J. Ericson, pp. 71-90. Academic Press, New York.

San Román, M. y A. Prieto 2004. (Dis)continuidad del uso de obsidiana verde entre poblaciones de adaptación marítima del mar de Otway y estrecho de Magallanes. En Contra Viento y Marea: Arqueología de Patagonia, editado por T. Civalero, P. Fernández y G. Guráieb, pp. 571-580. Instituto Nacional de Antropología y Pensamiento Latinoamericano y Sociedad Argentina de Antropología, Buenos Aires. 
Skarbun, F. 2009. Análisis de los conjuntos líticos del sitio La Mesada, Localidad Arqueológica La María, Meseta Central de Santa Cruz. En Arqueología de Patagonia: una Mirada desde el Último Confín, editado por M.C. Salemme, F. Santiago, M. Álvarez, E. Piana, M. Vazquez y M.E. Mansur, pp. 1177-1194. Editorial Utopías, Ushuaia.

Skarbun, F. 2011. La Organización Tecnológica en Grupos Cazadores Recolectores Desde las Ocupaciones del Pleistoceno Final al Holoceno Tardío, en la Meseta Central de Santa Cruz, Patagonia. Archaeopress. Publish of British Archaeological Reports, Oxford.

Stern, C.R. 1999. Black obsidian from Central-South Patagonia: Chemical characteristics, sources and regional distribution of artifacts. En Soplando en el Viento... Actas de las III Jornadas de Arqueología de Patagonia, editado por R. Goñi, pp. 221-234. Instituto Nacional de Antropología y Pensamiento Latinoamericano y Universidad Nacional del Comahue, NeuquénBuenos Aires.

Stern, C.R. 2004. Obsidian in Southern Patagonia: Review of the current information. En Contra Viento y Marea. Arqueología de Patagonia, editado por P. Civalero, P. Fernández y A.G. Guráieb, pp. 167-176. Instituto Nacional de Antropología y Pensamiento Latinoamericano y Sociedad Argentina de Antropología, Buenos Aires.
Stern, C.R. 2016. Geochemical analysis on obsidian samples from La María. Manuscrito en posesión del autor.

Stern, C.R. y N.V. Franco 2000. Obsidiana gris verdosa veteada en la cuenca superior del río Santa Cruz, extremo sur de Patagonia. Anales del Instituto de la Patagonia 28:265-273.

Stern, C.R. y C. Prieto 1991. Obsidiana verde de los sitios arqueológicos en los alrededores del mar de Otway, Magallanes, Chile. Anales del Instituto de la Patagonia 20:139-144.

Stern, C.R., A. Prieto y N.V. Franco 1995. Obsidiana negra en sitios arqueológicos de cazadores-recolectoes terrestres en Patagonia austral. Anales del Instituto de la Patagonia (Ser. Cs. Hs.) 23:105-109.

Tixier, J., M.L. Inizan y H. Roche 1980. Prehistoire de la Pierre Taille. Circle de Rechearches et d'etudes prehistoriques, Antibes, France.

Tykot, R. 1996. Obsidian procurement and distribution in the Central and Western Mediterranean. Journal of Mediterranean Archaeology 9:39-82.

Zubimendi, M. y P. Ambrústolo 2011. La presencia de Ítems marinos en el interior de la Patagonia Central. En Movilidad y Migraciones. Actas de las III Jornadas Multidisciplinarias, editado por C.A. Guiance, pp. 291-305. CONICET-IMICIHU.

\section{Nota}

